This is the submitted version of the following article:

Israr M., Iqbal J., Arshad A., Aisida S. O., Ahmad I.. A unique ZnFe2O4/graphene nanoplatelets nanocomposite for electrochemical energy storage and efficient visible light driven catalysis for the degradation of organic noxious in wastewater. Journal of Physics and Chemistry of Solids, (2020). 140.

109333: - . 10.1016/j.jpcs.2020.109333,

which has been published in final form at https://dx.doi.org/10.1016/j.jpcs.2020.109333 @ https://dx.doi.org/10.1016/j.jpcs.2020.109333. This manuscript version is made available under the CC-BY-NC-ND 4.0 license http: // creativecommons.org/licenses/by-nc-nd/4.0/ 


\title{
A unique $\mathrm{ZnFe}_{2} \mathrm{O}_{4} /$ graphene nanoplatelets nanocomposite for electrochemical energy storage and efficient visible light driven catalysis for the degradation of organic noxious in wastewater
}

\author{
M. Israr ${ }^{1,2}$, Javed Iqbal ${ }^{1, *}$, Aqsa Arshad ${ }^{3}$, Samson O. Aisida ${ }^{1,4,5}$, Ishaq Ahmad ${ }^{5,6}$ \\ ${ }^{1}$ LNT, Department of Physics, Quaid-i-Azam University, Islamabad, Pakistan \\ ${ }^{2}$ Catalan Institute of Nanoscience and Nanotechnology, Autonomous University of Barcelona, Spain \\ ${ }^{3}$ Department of Physics, International Islamic University, Islamabad, Pakistan \\ ${ }^{4}$ Department of Physics and Astronomy, University of Nigeria, Nsukka, Nigeria \\ ${ }^{5}$ National Center for Physics (NCP), Quaid-i-Azam University, Islamabad, Pakistan
}

${ }^{6}$ NPU-NCP Joint International Research Center on Advanced Nanomaterials and Defects Engineering, Northwestern Polytechnical University, Xi'an 710072, China

*Corresponding author: javed.saggu@qau.edu.pk

\begin{abstract}
A series of $\mathrm{ZnFe}_{2} \mathrm{O}_{4} /$ graphene nanoplatelets $\left((\mathrm{ZF})_{1-\mathrm{x}}(\mathrm{GNPs})_{\mathrm{x}}\right)$ nanocomposites have been synthesized and characterized. By optimizing the weight ratio of graphene nanoplatelets (GNPs), the synthesized nanocomposites have been identified as an excellent material for electrochemical capacitors with maximum electrochemical capacitance $\left(314 \mathrm{Fg}^{-1}\right.$ at $\left.0.5 \mathrm{~A} \mathrm{~g} \mathrm{~g}^{-1}\right)$, high rate performance, and long-standing cyclic stability (77.6\% retention). The enhanced electrochemical performance might be adduced to the improved electrode/electrolyte charge transfer interface and conducting nature of GNPs. Besides, $(\mathrm{ZF})_{1-\mathrm{x}}(\mathrm{GNPs})_{\mathrm{x}}$ nanocomposites exhibited outstanding visible light driven photocatalytic efficiency for the removal of methylene blue (MB) dye in water i.e., $97.46 \%$ of the $\mathrm{MB}$ is degraded in $70 \mathrm{~min}$, which can be primarily ascribed to the enhanced photo Fenton reaction, effective electron-hole $\left(\mathrm{e}^{-} / \mathrm{h}^{+}\right)$separation and strong interfacial coupling between $\mathrm{ZnFe}_{2} \mathrm{O}_{4}$ nanoparticles (ZF NPs) and GNPs. Our results offer new insights into the fabrication of novel multifunctional nanocomposites for the electrochemical energy storage and treatment of polluted wastewater.
\end{abstract}

Keywords: Nanocomposites; Electrochemical properties; Photocatalysis; Graphene nanoplatelets; Zn ferrite.

\section{Highlights}

$\mathrm{ZnFe}_{2} \mathrm{O}_{4} /$ graphene nanoplatelets nanocomposites, $(\mathrm{ZF})_{1-\mathrm{x}}(\mathrm{GNPs})_{\mathrm{x}}$ were prepared. 
The $(\mathrm{ZF})_{1-\mathrm{x}}(\mathrm{GNPs})_{\mathrm{x}}$ nanocomposite electrode, with $\mathrm{x}=0.75$, exhibits an exceptional supercapacitive performance, with enhanced electrochemical capacitance $\left(314 \mathrm{Fg}^{-1}\right.$ at 0.5 $\left.\mathrm{Ag}^{-1}\right)$, high rate performance, and long-standing cycling stability (77.6\% retention of the initial specific capacitance).

$>$ The $(\mathrm{ZF})_{1-\mathrm{x}}(\mathrm{GNPs})_{\mathrm{x}}$ nanocomposite, with $\mathrm{x}=0.50$, shows excellent photocatalytic activity (97.46\% MB degradation in $70 \mathrm{~min}$ ) under visible light as compared to neat $\mathrm{ZF}$ NPs.

$>$ High surface area, interfacial charge transfer and $\mathrm{e}^{-} / \mathrm{h}^{+}$separation are the governing factors for the high performance as supercapacitor and photocatalyst.

\section{Introduction}

Electrochemical energy storage systems, based on the adaptation of renewable energy solutions, find many applications ranging from energy storages at grid-scale to consumer electronics [1]. Supercapacitors with good cycling stability, rapid rechargeability, and high power density are highly in demand, for energy storage applications [2, 3]. Electrode-based materials are basically of two types: carbon-based electrochemical double layer (ECDL) and pseudocapacitive materials e.g. transition metal oxides. The ECDL supercapacitance emanates from the buildup of charges at the interface between electrode and electrolyte ; whereas, pseudocapacitance is a consequence of reversible faradic reactions, at the surface of electrode [4]. Carbonaceous materials with porous structures have been the most researched materials as supercapacitor electrodes [5]. However, low energy density hinders their large-scale application. Conducting polymers and metal oxides have been preferred for application in pseudo-capacitors because of Faradic charge storage mechanism [6-9]. Among metal based oxides, ferrites have shown prodigious potential for electrochemical applications due to their spinel structure and good stability [10]. $\mathrm{Zn}$ ferrite $\left(\mathrm{ZnFe}_{2} \mathrm{O}_{4}\right)$ is the most competitive material for electrochemical applications because of its non-toxic nature, abundant resources, low cost, and high theoretical capacity (2600 $\mathrm{Fg}^{-1}$ ) [11-15]. Unfortunately, its poor conductivity and volume change during charge/discharge cycles make it unsuitable for practical supercapacitors [16]. Graphene, due to its conducting nature, large specific surface area, and outstanding electrochemical stability, has been proved to be perfect when combined with metal oxides nanostructures. The pristine $\mathrm{Zn}$ ferrite electrodes exhibit poor rate performance and cycling stability, however, grafting them onto graphene can effectively boost the electrochemical properties. As for the $\mathrm{ZnFe}_{2} \mathrm{O}_{4} /$ graphene 
system, the related study on the effective control over interfacial interaction and understanding the influence of graphene loading ratio on the electrochemical properties is researchable topic.

Nowadays, water pollution is among the main environmental challenges confronted by society $[17,18]$ Exposure to these toxic materials causes various neurological and immunological disorders in living organisms $[19,20]$. Therefore, removal of these organic containments from wastewater is extremely important and urgent. Among various water purification technologies, visible light driven photocatalysis is an effective and cheap solution to the problem of water pollution. Ferrites have been extensively used as photocatalysts due to their chemical stability and easy magnetic separation [21-23]. However, the limitations are associated with the high resistivity, agglomeration, and fast charge carrier recombination [24, 25]. Therefore, photocatalysts with a conductive constituent component such as graphene, CNTs etc. are attracting attention due to their high photocatalytic activities and eco-friendliness [26-29]. $\mathrm{ZnFe}_{2} \mathrm{O}_{4}$-graphene nanocomposites have been successfully used as a photocatalysts agent in the degradation of number of organic dyes [30-32]. However, the reported synthesis protocols of $\mathrm{ZnFe}_{2} \mathrm{O}_{4}$-graphene composites till date require high-pressure processes, which are not ideal for large scale production for sundry applications [33].

In this work, the in-situ fabricated $(\mathrm{ZF})_{1-\mathrm{x}}(\mathrm{GNPs})_{\mathrm{x}}$ nanocomposites are presented as an excellent electrode material for supercapacitors and visible light photocatalyst for the degradation of $\mathrm{MB}$ dye. The enhanced supercapacitive and photocatalytic performance has been explained, based on physiochemical characteristics, interfacial charge transfer, carrier generation, and electronic coupling of the constituents of the nanocomposite system.

\section{Experimental Methods}

\subsection{Synthesis of $(\mathrm{ZF})_{1-\mathrm{x}}(\mathrm{GNPs})_{\mathrm{x}}$ Nanocomposite}

Analytical grade chemicals acquainted from Sigma-Aldrich, have been used without further purification. $(\mathrm{ZF})_{1-\mathrm{x}}(\mathrm{GNPs})_{\mathrm{x}}$ nanocomposites with varying weight ratios i.e. 25 ( $\mathrm{x}=0.25$ ), $50(x=0.50)$, and $75 \%(x=0.75)$ of GNPs have been prepared through in-situ grafting of ZF NPs using co-precipitation method [34]. (ZF) $)_{1-x}(\mathrm{GNPs})_{\mathrm{x}}$ nanocomposite with 25 wt. \% GNPs has been prepared by the following procedure: Typically, $400 \mathrm{mg}$ GNPs (99.9\%) purchased from KNano were dispersed in a mixed aqueous solution of CTAB $(0.1 \mathrm{~g})$ and $\mathrm{NaOH}(6 \mathrm{M})$ under 
ultra-sonication for $3 \mathrm{~h}$. The mixture was then slowly heated to $80^{\circ} \mathrm{C}$ followed by dropwise addition of a mixed aqueous solution containing $\mathrm{Fe}\left(\mathrm{NO}_{3}\right)_{3} \cdot 9 \mathrm{H}_{2} \mathrm{O}(200 \mathrm{mM})$ and $\mathrm{Zn}\left(\mathrm{NO}_{3}\right)_{2} \cdot 6 \mathrm{H}_{2} \mathrm{O}$ $(100 \mathrm{mM})$. The temperature of the solution was maintained at $80^{\circ} \mathrm{C}$ for $2 \mathrm{~h}$ under magnetic stirring. The nanoparticles formed were washed 5 times with ethanol and distilled water followed by desiccating at $100^{\circ} \mathrm{C}$ for $6 \mathrm{~h}$. The obtained powdered sample was then annealed at $350^{\circ} \mathrm{C}$ in $\mathrm{N}_{2}$ atmosphere for $5 \mathrm{~h}$ using a tube furnace. The nanocomposites with 0,50 , and $75 \%$ GNPs has been synthesized using a similar method.

\subsection{General Characterizations}

The crystallographic identification of the obtained products was carried out using X-ray diffraction under $\mathrm{Cu} \mathrm{K \alpha}$ radiation $(\lambda=1.5406 \AA)$ on a Malvern PANalytical X'pert X-ray diffractometer. The morphology of the composites has been observed by a TEM (Thermo Fisher ). Room temperature XPS spectrographs have been recorded with (SPECS GmbH, Berlin, Germany) using $\mathrm{Al} \mathrm{K}_{\alpha}(1486.74 \mathrm{eV})$ radiations . Optical characteristics of the composites have been studied with the help of diffused reflectance spectroscopy using (LAMBDA 850 UV/vis Spectrophotometer). The Photoluminescence (PL) spectra analysis was obtained to study luminescent characteristics of the obtained materials with JASCO FP-6300 fluorescence spectrometer.

\subsection{Electrochemical measurements analysis}

Room temperature supercapacitive properties of the synthesized samples have been evaluated at in two electrode systems using $0.5 \mathrm{M} \mathrm{K}_{2} \mathrm{SO}_{4}$ as an electrolyte. Following procedure has been used to prepare working electrodes of the prepared samples. Typically, $70 \mathrm{wt}$ \% (ZF)1x (GNPs $)_{x}, 15$ wt. \% of polyvinylidene fluoride (PVDF) was used as a binder) and 15 wt. \% carbon super $\mathrm{P}$ (as electrically conductive agent) were mixed in N-methyl-2-pyrrolidinone (NMP) and were stirred overnight to form a homogenous mixture. The uniform mixture in the form of paste was transferred to aluminum foil using doctor blade technique to form a thin layer of the working electrode and dried at $80^{\circ} \mathrm{C}$ for 24 hours in vacuum. Glass microfiber sheet was used as a separator between the two electrodes during the measurements. A multichannel potentiostat (Biologic VMP3) was used to measure electrochemical properties. 


\subsection{Measurement of photocatalytic activity}

Photocatalytic performance of all the synthesized samples were evaluated under visible light irradiation by the removal of MB dye The degradation efficiency of the prepared samples was evaluated with $30 \mathrm{mg}$ of the prepared photocatalyst dissolved in $100 \mathrm{~mL}(20 \mathrm{mg} / \mathrm{L})$ of $\mathrm{MB}$ dye aqueous solution followed by continuous stirring in the dark for $30 \mathrm{~min}$ to attain adsorption and desorption equilibrium. Afterwards, the photocatalytic performance was investigated by irradiating the formed solution with the xenon lamp. During the visible light irradiation, about the reaction solution (about $4 \mathrm{~mL}$ ) was taken every $10 \mathrm{~min}$, and the photocatalyst was removed from it. The variations in the absorption band up to the maximum $(664 \mathrm{~nm})$ in the UV-visible spectra of MB were noted for the analysis of the photo-reacted MB solution.

\section{Results and discussions}

\subsection{XRD analysis}

The structural nature of the prepared nanocomposites has been studied by using a powder X-ray diffraction analysis, as given in Fig. 1. The obvious diffraction peaks are at $2 \theta=29.9^{\circ}, 35.3^{\circ}$, $42.9^{\circ}, 53.2^{\circ}, 56.6^{\circ}$ and $62.2^{\circ}$ attributed to (220), (311), (400), (422), (511), and (440) lattice planes of the ZF NPs respectively. The XRD diffraction profiles are well consistent with the standard pattern of spinel ZF NPs (JCPDS No. 22-1012) in all the samples [30]. The absence of any peak related to impurities verifies that the pure phase samples were successfully formed. Furthermore, the peak observed in the composite samples at $2 \theta=26.3^{\circ}$ (002 plane of GNPs), confirms the effective formation of ZF and GNPs nanocomposites.

\subsection{TEM results analysis}

The morphological and surface characteristics of the prepared $(\mathrm{ZF})_{1-\mathrm{x}}(\mathrm{GNPs})_{\mathrm{x}}$ samples have been studied using TEM technique, and the results are shown in Fig. 2. The as-prepared ZF NPs consist of quasi-spherical particles with size range, $11 \mathrm{~nm}-19 \mathrm{~nm}$. It is clear from the TEM images of the composite samples that many ZF NPs are uniformly anchored to the surface of GNPs. As shown in the inset of Fig.2, the HRTEM image of the as-prepared ZF NPs sample shows perfect lattice fringes, suggesting its highly crystalline nature. The spacing between lattice 
fringes has been found to be $0.254 \mathrm{~nm}$, which corresponds to the $(331)$ plane of $\mathrm{ZF}[35,36]$. This is in agreement with the results of XRD measurements.

\subsection{XPS results analysis}

The valence state and chemical composition of prepared nanomaterials were investigated using XPS measurements as given in Fig. 3. The two clear peaks at $1021.6 \mathrm{eV}$ and $1044.7 \mathrm{eV}$ can be adduced to $\mathrm{Zn} 2 \mathrm{p}_{3 / 2}$ and $\mathrm{Zn} 2 \mathrm{p}_{1 / 2}$ of $\mathrm{ZF}$ NPs [37]. The wide angle spectrum of Fe $2 \mathrm{p}$ given in Fig.3 shows two distinct peaks centered at $711.36 \mathrm{eV}$ and $725.3 \mathrm{eV}$, which are consigned to $\mathrm{Fe} 2 \mathrm{p}_{3 / 2}$ and $\mathrm{Fe} 2 \mathrm{p}_{1 / 2}$. The satellite peaks present in $\mathrm{Fe} 2 \mathrm{p}$ spectrum verifies the presence of $\mathrm{Fe}^{+3}$ oxidation state in the prepared samples [38]. Slight shift in binding energy of $\mathrm{Zn}$ $2 \mathrm{p}$ peaks has been observed when ZF NPs were composited with GNPs. This shift in binding energy occurs due to the screening effect as a consequence of joining two different semiconductors. Upon joining (compositing) two semiconductors, electrons go from one semiconductor to the other, so that the Fermi level of both semiconductors attain the same value. This electron flow changes the density of electrons in the composting materials. The change in electron density shift the binding energies of the constituent atoms [39]. The O1s peak in the high-resolution spectra of typical $(\mathrm{ZF})_{50}(\mathrm{GNPs})_{50}$ sample deconvoluted to three components located at $530.1 \mathrm{eV}$ (metal-oxygen bond), $531.9 \mathrm{eV}$ (hydroxyl groups adsorbed) and $533.7 \mathrm{eV}$ (the surface-adsorbed oxygen) respectively [40]. In the C1s spectrum the peaks located at 284.39 and $285 \mathrm{eV}$ reveals the presence of $\mathrm{sp}^{2} \mathrm{C}=\mathrm{C}$ and $\mathrm{sp}^{3} \mathrm{C}-\mathrm{C}$ bonds, respectively [41-43]. The XPS results confirm that there is certain chemical as well as electronic interaction of the anchored $\mathrm{ZF}$ NPs with the GNPs, which is beneficial to exploit the synergistic effects of the constituents of the nanocomposite in applications such as photocatalysis and supercapacitors.

\subsection{Optical properties}

The optical properties of the formulated samples have been explored using DRS, and the results are shown in Fig. 4(a). It is obvious from the DRS results that pristine ZF as well the composite samples exhibited good absorption in both UV and visible part of light spectrum. The band gap energy has been calculated using the Kubelka-Munk (KM) function (Eq. 1) [40]

$$
F(R)=\frac{(1-R)^{2}}{2 R}
$$


Here measured reflectance is represented by $\mathrm{R}$. The plot between $[F(R) h v]^{2}$ and $h v$ gives the band gap of the formulated nanoparticles as given in the Fig. 4(b). The obtained values of band gap were estimated to be 2.06, 2.02, 2.01, and $1.98 \mathrm{eV}$ for $(\mathrm{ZF})_{1-\mathrm{x}}(\mathrm{GNPs})_{\mathrm{x}}$ samples. A slight decrease in bandgap energy has been observed with the increasing content of graphene. This graphene induced decrease in band gap has been reported previously [44], which can be attributed to the formation of extra mid-gap energy in ZF NPs as a result of its chemical interaction with GNPs [45-47].

\subsection{Photoluminescence spectroscopy (PL) result analysis}

PL spectroscopy is a valuable technique for the examination of key characteristics of the materials related to the charge carrier transportation and recombination [48]. The PL emission primarily results from the radiative recombination of the excited $\mathrm{e}^{-}$and $\mathrm{h}^{+}$, as shown in Fig. 5. The PL intensity for $388.5 \mathrm{~nm}$ peak decreases as the graphene ratio increases, which implies that the photo generated $\mathrm{e}^{-/ \mathrm{h}^{+}}$pairs recombination is greatly hindered when GNPs are introduced along with ZF NPs [49]. The decreased of $\mathrm{e}^{-/ \mathrm{h}^{+}}$recombination can be ascribed to the electron accepting nature of graphene. In the composite sample, the electrons valence band of ZF are readily accepted by GNPs instead of recombining [50], which reduces the recombination rate of $\mathrm{e}^{-}$and $\mathrm{h}^{+}$pairs and consequently the PL intensity decreases. This behavior of nanocomposites is a strong indication of nanocomposites' tendency towards efficient photodegradation.

\section{Electrochemical Properties}

\subsection{Cyclic Voltammetry (CV)}

Fig. 6 depicts the comparison of CV profiles of the as-prepared ZF NPs and the nanocomposite electrodes measured at $5 \mathrm{mVs}^{-1}$. Obviously, all the $\mathrm{CV}$ profiles deviated from the rectangular shape, suggesting a pseudo-capacitive mechanism of the dominant charge. The integrated area under the $\mathrm{CV}$ curve is maximum for $(\mathrm{ZF})_{0.50}(\mathrm{GNPs})_{0.50}$, which depicts its superior specific capacitance. CV curves for the as-prepared $\mathrm{ZF}$ and the composite electrodes at various scan rate are presented in Fig. 7 (a)-(e). It is clear from the figure that the shape of CV curve is maintained for $(\mathrm{ZF})_{0.50}$ (GNPs) $)_{0.50}$ electrode even at a very high scan rate, signifying its higher rate proficiency. It is imperative to highlight that the greater specific capacitance and high rate proficiency might be adduced to the conducting graphene network formed within the 
nanocomposite structure. The highly conducting GNPs within the nanocomposite system makes charge transport efficient, which, as a consequence, improves the rate capability of the electrode.

\subsection{Galvanostatic charge/discharge (GCD) curves Study}

GCD is a robust technique to quantify the electrochemical capacitance of materials. A comparison of the GCD curves of ZF as-prepared and the $(\mathrm{ZF})_{1-\mathrm{x}}(\mathrm{GNPs})_{\mathrm{x}}$ nanocomposites at the current density of $0.5 \mathrm{Ag}^{-1}$ is presented in Fig. 8. It should be noted that $(\mathrm{ZF})_{50}(\mathrm{GNPs})_{50}$ electrode shows the longest lengthiest discharging time among all the prepared materials, indicating its highest specific capacitance. The specific capacitance of a single electrode has been obtained from the GCD curves using Eq. 2 [49],

$$
C_{s}=\frac{4 I \Delta t}{m \Delta V}=4 C_{T}
$$

Where $\Delta t=$ discharge time (s), $I=$ current (A), $\Delta V=$ applied potential (V), $\quad m=$ total mass of the active material in both electrodes $(\mathrm{g})$ and $C_{T}=$ capacitance of the cell. The calculated specific capacitance from the discharge portion of GDC curves for ZF and (ZF)1${ }_{\mathrm{x}}(\mathrm{GNPs})_{\mathrm{x}}$ are $134 \mathrm{Fg}^{-1}, 192 \mathrm{Fg}^{-1}, 314 \mathrm{Fg}^{-1}$, and $82 \mathrm{Fg}^{-1}$ respectively. The specific capacitance was observed to decreases as the graphene content is increased beyond $50 \%$, which may be due to the restocking of graphene sheets, at high loading ratios and inferior specific capacitance of GNPs [51]. The various current densities of GCD curves of the prepared ZF and the composite electrodes are presented in Fig. 9 (a)-(e), while Fig. 10 (a) shows the specific capacitance for all the prepared samples with changing current density. It is obvious from the Figure 10 (a) that $(\mathrm{ZF})_{50}(\mathrm{GNPs})_{50}$ sample shows the high value of specific capacitance even at greater current density, indicating its high rate capability. These results suggest that the optimal concentration of graphene content for achieving high electrochemical capacitance and rate capability is $50 \mathrm{wt} \%$. The reason behind the enhanced electrochemical properties at this optimum composition might be the better dispersion of ZF NPs over the surface of GNPs and improved interaction at the nano-interfaces. 


\subsection{Energy and Power Density analysis}

The energy and power density of a supercapacitor cell were obtained using Eq. 3 and 4 [52]

$$
\begin{aligned}
& E=\frac{0.5 \mathrm{C}_{\mathrm{T}}(\Delta V)^{2}}{3.6} \\
& P=\frac{E}{\Delta \mathrm{t}}
\end{aligned}
$$

Where $E=$ average energy density $\left(\mathrm{Wh} \mathrm{kg}^{-1}\right), C_{T}=$ the specific capacitance of the cell, $\Delta V=$ the potential window of discharge $(\mathrm{V}), P=$ power density $\left(\mathrm{Wkg}^{-1}\right), \Delta t=\operatorname{discharge}$ time $(\mathrm{s})$. The energy density vs power density plot for $\mathrm{ZF}$ and the $(\mathrm{ZF})_{1-\mathrm{x}}(\mathrm{GNPs})_{\mathrm{x}}$ nanocomposites is presented in Fig. 10 (b). The energy density calculated for ZF and (ZF) $)_{1-\mathrm{x}}(\mathrm{GNPs})_{\mathrm{x}}$ electrodes are 2.6, 6.7, 10.9, and $2.8 \mathrm{Whkg}^{-1}$ at $125 \mathrm{Wkg}^{-1}$ power density, respectively. The highest value of the energy density, obtained at an optimum concentration of $50 \mathrm{wt}$. \% GNPs ratio can be attributed to the enhanced pseudo-capacitance, which may occur as a consequence of well distributed ZF nanoparticles over the surface of GNPs.

\subsection{Electrochemical impedance spectroscopy (EIS) analysis}

EIS technique is highly useful to examine the resistive behavior of the electrodes. EIS measurements for the prepared $(\mathrm{ZF})_{1-\mathrm{x}}(\mathrm{GNPs})_{\mathrm{x}}$ electrodes were obtained in the range $0.1 \mathrm{~Hz}-$ $100 \mathrm{kHz}$, and the obtained results are given in Fig. 11 (a). Obviously, EIS spectra of all the samples show a semicircular part and a linear portion. Interestingly, the linear portion of the $(\mathrm{ZF})_{50}(\mathrm{GNPs})_{50}$ sample is more vertically inclined as compared to that of other samples, which indicates that its diffusive resistance is lowest [53]. Furthermore, the smallest diameter of the semicircular portion for the $(\mathrm{ZF})_{50}(\mathrm{GNPs})_{50}$ electrode confirms fast charge transfer [54]. The smaller resistance to charge transfer for the $(\mathrm{ZF})_{1-\mathrm{x}}(\mathrm{GNPs})_{\mathrm{x}}$ nanocomposite electrodes indicates the beneficial role of introducing GNPs to the neat ZF nanoparticles. Here, GNPs act as conducting backbone to lower the resistivity of the nanocomposite system. This improved conductivity, in turn, improves the electrochemical output of the composite electrode.

\subsection{Cyclic performance}


The cyclic life is another key performance indicator for practical application and commercialization of electrode materials. The cycle stability test was performed for over 1500 cycles at $5 \mathrm{Ag}^{-1}$ for the best performing (ZF) $)_{50}(\mathrm{GNPs})_{50}$ electrode. Fig. 11 (b) displays capacitive retention of the $(\mathrm{ZF})_{50}(\mathrm{GNPs})_{50}$ electrode, which shows that after 1500 continuous charging and discharging cycles, $77.6 \%$ of the specific capacitance the first cycle is retained. Here, the GNPs play a critical role in preventing the volume changes occurring during the reversible redox process, subsequently enhancing the cycling performance $[55,56]$. It is clear from the experimental findings that this superior supercapacitive performance of the synthesized $(\mathrm{ZF})_{1-}$ ${ }_{\mathrm{x}}(\mathrm{GNPs})_{\mathrm{x}}$ composite materials could be ascribed to the following reasons: Firstly, the CTAB assisted in-situ grafting of the ZF NPs to the surface of GNPs, offers an effective interfacial interaction between composited components. Secondly, the well-distributed GNPs provide a high specific surface area in the $(\mathrm{ZF})_{1-\mathrm{x}}(\mathrm{GNPs})_{\mathrm{x}}$ composites, and conductive pathway to the flow of charges, that result in fast transportation of ions and electrons during the electrochemical process. Thirdly, the porous morphology offered by the nanocomposite structure facilitates ion diffusion to the inner surface of the electrode, enabling full utilization of the electrode material [57].

Hence, the exceptional electrochemical enactment of $(\mathrm{ZF})_{1-\mathrm{x}}(\mathrm{GNPs})_{\mathrm{x}}$ nanocomposites stemmed from the synergistic behavior of ZF NPs and GNPs. Notably, the ZF NPs grafted to GNPs might efficiently inhibit restacking of GNPs, which increases the effective surface area and as a consequence ECDL contribution of GNPs to the overall specific capacitance is increased. While, GNPs with highly conducting nature could help in improving rate performance and cyclic stability of the nanocomposite electrode.

\section{Photocatalytic activity test}

The comparison of the photodegradation efficiency of as-prepared ZF NPs and the composite samples is shown in Fig. 12. Clearly, the degradation efficiency for neat ZF NPs and GNPs is $31.3 \%$ and $19 \%$ respectively after $70 \mathrm{~min}$ of visible irradiation. Whereas, for the $(\mathrm{ZF})_{1-}$ ${ }_{\mathrm{x}}(\mathrm{GNPs})_{\mathrm{x}}$ samples, the degradation efficiencies are $97.46 \%, 85.4 \%$, and $53.4 \%$ for the prepared $(\mathrm{ZF})_{1-\mathrm{x}}(\mathrm{GNPs})_{\mathrm{x}}$ respectively. Obviously, photocatalytic activity is highest for $(\mathrm{ZF})_{0.75}(\mathrm{GNPs})_{0.25}$ nanocomposite sample. It is notable that the photocatalytic activity decreases when the graphene content is further increased to $50 \%$ and $75 \%$. This decrease in photodegradation efficiency with a 
high content of graphene is in agreement with previous reports and can be ascribed to the visible light shielding produced by the GNPs [58]. The absorption spectra of MB at various irradiation time intervals are given in Fig. 13 (a)-(e). It is important to describe that the remarkable enhancement in photodegradation of the organic dye can be ascribed to photo Fenton reaction, fast charge separation, and the synergistic electronic interaction between constituent composite materials. The electrons are transferred between ZF NPs and GNPs, which facilitates the reversible reduction of $\mathrm{Fe}^{3+}$ to $\mathrm{Fe}^{2+}$ ions. Consequently, $\mathrm{Fe}^{2+}$ would react with $\mathrm{H}_{2} \mathrm{O}_{2}$ to yield reactive oxygen species such as hydroxyl radicals $(\bullet \mathrm{OH})$ etc as a result of the photo-Fenton reaction and reduces the adsorbed dye producing $\mathrm{CO}_{2}$ and $\mathrm{H}_{2} \mathrm{O}$ as a final product [59]. The proposed photocatalytic degradation mechanism of MB is shown in Fig.14. All these factors together account for excellent photocatalytic activity of ZF and GNPs nanocomposite.

\section{Conclusion}

Novel multifunctional $(\mathrm{ZF})_{1-\mathrm{x}}(\mathrm{GNPs})_{\mathrm{x}}$ nanocomposites having different GNPs loading ratios have been fabricated successfully via facile and cost-effective method. The morphological study indicates that GNPs are decorated with ZF NPs. The electrochemical measurements show that the combination of ZF NPs and GNPs, as composite material, significantly enhances supercapaciting properties as compared to neat ZF NPs. However, maximum enhancement was achieved in case of $(\mathrm{ZF})_{50}(\mathrm{GNPs})_{50}$ with optimized GNPs ratio. Furthermore, the $(\mathrm{ZF})_{1-\mathrm{x}}(\mathrm{GNPs})_{\mathrm{x}}$ nanocomposite, with $(\mathrm{x}=0.25)$ demonstrated an excellent photocatalytic degradation of $\mathrm{MB}$ using visible light. The superior supercapacitive and photocatalytic performance of the $(\mathrm{ZF})_{1 \text { - }}$ ${ }_{\mathrm{x}}(\mathrm{GNPs})_{\mathrm{x}}$ nanocomposites has been assigned to their unique structural morphology with high surface area and outstanding synergistic interaction between the ZF NPs and the GNPs.

\section{Acknowledgments}

M. I acknowledges the Higher Education Commission of Pakistan (HEC) IRSIP (Grant No: 18/HEC/HRD/2017/8412 PIN: IRSIP 39 PSc 15). J. I acknowledges the Higher Education Commission of Pakistan (HEC) NRPU (Grant No: 20-4861/R\&D/HEC/14). S. O. A acknowledges the NCP-TWAS Postdoc Fellowship award (NCP-CAAD/TWAS_Fellow8408). 


\section{References}

1. Chodankar, N.R., et al., Highly efficient and stable negative electrode for asymmetric supercapacitors based on graphene/FeCo2O4 nanocomposite hybrid material. Electrochimica Acta, 2019. 295: p. 195-203.

2. Miller, J.R. and P.J.S. Simon, Electrochemical capacitors for energy management. Science, 2008. 321(5889): p. 651-652.

3. Zhang, J., et al., The graphene/lanthanum oxide nanocomposites as electrode materials of supercapacitors. Journal of Power Sources, 2019. 419: p. 99-105.

4. Hua, X., et al., Facile synthesis of new-type MnOOH/NiAl-layered double hydroxide nanocomposite for high-performance supercapacitor. Journal of Alloys and Compounds, 2019. 777: p. 749-758.

5. Kou, Z., et al., Molybdenum carbide-derived chlorine-doped ordered mesoporous carbon with few-layered graphene walls for energy storage applications. ACS applied materials \& interfaces, 2017. 9(4): p. 3702-3712.

6. Zou, Y., et al., Simple synthesis of core-shell structure of Co-Co3O4@ carbon-nanotubeincorporated nitrogen-doped carbon for high-performance supercapacitor. Electrochimica Acta, 2018. 261: p. 537-547.

7. Ouyang, Y., et al., Hierarchical structure electrodes of NiO ultrathin nanosheets anchored to NiCo2O4 on carbon cloth with excellent cycle stability for asymmetric supercapacitors. Chemical Engineering Journal, 2019. 355: p. 416-427.

8. Ouyang, Y., et al., Hierarchical electrodes of NiCo 2 S 4 nanosheets-anchored sulfurdoped Co 3 O 4 nanoneedles with advanced performance for battery-supercapacitor hybrid devices. Journal of Materials Chemistry, 2019. 7(7): p. 3228-3237.

9. Zhao, P., et al., Nanocomposites of hierarchical ultrathin MnO2 nanosheets/hollow carbon nanofibers for high-performance asymmetric supercapacitors. Applied Surface Science, 2019. 463: p. 931-938.

10. Thu, T.V., et al., Graphene-MnFe2O4-polypyrrole ternary hybrids with synergistic effect for supercapacitor electrode. Electrochimica Acta, 2019. 314: p. 151-160.

11. Vadiyar, M.M., et al., Reflux condensation mediated deposition of Co3O4 nanosheets and $\mathrm{ZnFe} 2 \mathrm{O} 4$ nanoflakes electrodes for flexible asymmetric supercapacitor. Electrochimica Acta, 2016. 222: p. 1604-1615.

12. Vadiyar, M., et al., Mechanochemical growth of a porous ZnFe 2 O 4 nano-flake thin film as an electrode for supercapacitor application. RSC Advances, 2015. 5(57): p. 4593545942.

13. Raut, S.S. and B.R.J.E.A. Sankapal, First report on synthesis of ZnFe2O4 thin film using successive ionic layer adsorption and reaction: approach towards solid-state symmetric supercapacitor device. Electrochimica Acta, 2016. 198: p. 203-211.

14. Rani, B.J., et al., Pure and cobalt-substituted zinc-ferrite magnetic ceramics for supercapacitor applications. Applied Physics A, 2018. 124(7): p. 511.

15. Zhang, D., et al., A facile strategy for ZnFe $2 O 4$ coating preparing by electrophoretic deposition and its supercapacitor performances. Journal of Materials Science: Materials in Electronics, 2018. 29(7): p. 5454-5458. 
16. Raut, S.S., et al., Zinc ferrite anchored multiwalled carbon nanotubes for highperformance supercapacitor applications. European Journal of Inorganic Chemistry, 2018. 2018(2): p. 137-142.

17. Wang, S., et al., Enhanced photocatalytic performance by hybridization of Bi2WO6 nanoparticles with honeycomb-like porous carbon skeleton. Journal of environmental management, 2019. 248: p. 109341.

18. Singh, A. and A. Sinha, Synthesis and characterization of CdS-based ternary composite for enhanced visible light-driven photocatalysis. Journal of Physics and Chemistry of Solids, 2018. 120: p. 123-132.

19. Lee, K.M., et al., Recent developments of zinc oxide based photocatalyst in water treatment technology: a review. Water research, 2016. 88: p. 428-448.

20. Yan, Y., et al., NaBH4-Reduction Induced Evolution of Bi Nanoparticles from BiOCl Nanoplates and Construction of Promising Bi@BiOCl Hybrid Photocatalysts. Catalysts, 2019. 9(10): p. 795.

21. Anwar, A., et al., New Er3+-substituted NiFe2O4 Nanoparticles and their Nanoheterostructures with Graphene for Visible Light-Driven Photo-catalysis and other Potential Applications. Current Nanoscience, 2019. 15(3): p. 267-278.

22. Huang, Y., et al., Synthesis of silver phosphate/sillenite bismuth ferrite/graphene oxide nanocomposite and its enhanced visible light photocatalytic mechanism. Separation and Purification Technology, 2019. 215: p. 490-499.

23. Huong, P.T.L., et al., Functional manganese ferrite/graphene oxide nanocomposites: effects of graphene oxide on the adsorption mechanisms of organic $M B$ dye and inorganic As (v) ions from aqueous solution. RSC advances, 2018. 8(22): p. 1237612389.

24. Liang, J., et al., Scalable green method to fabricate magnetically separable NiFe2O4reduced graphene oxide nanocomposites with enhanced photocatalytic performance driven by visible light. Industrial \& Engineering Chemistry Research, 2018. 57(12): p. 4311-4319.

25. Baghchesara, M.A., et al., Improving the intrinsic properties of $r G O$ sheets by $S$-doping and the effects of $r G O$ improvements on the photocatalytic performance of $\mathrm{Cu} 3 \mathrm{Se} 2 / \mathrm{rGO}$ nanocomposites. Applied Surface Science, 2019. 466: p. 401-410.

26. Behera, A., et al., Synergistic ZnFe2O4-carbon allotropes nanocomposite photocatalyst for norfloxacin degradation and $\mathrm{Cr}$ (VI) reduction. Journal of colloid and interface science, 2019. 544: p. 96-111.

27. Devi, L.G.J.S. and Interfaces, Impact of preparative $\mathrm{pH}$ conditions on the structure and morphology of Graphene oxide-CoFe2O4 composite: Exploration of adsorption isotherm models and photocatalysis. Surfaces and Interfaces 2019. 14: p. 175-183.

28. Yousefi, R., et al., Experimental and theoretical study of enhanced photocatalytic activity of $\mathrm{Mg}$-doped $\mathrm{ZnO} \mathrm{NPs}$ and $\mathrm{ZnO} / \mathrm{rGO}$ nanocomposites. Chemistry-An Asian Journal, 2018. 13(2): p. 194-203.

29. Yousefi, R., et al., The effect of defect emissions on enhancement photocatalytic performance of ZnSe QDs and ZnSe/rGO nanocomposites. Applied Surface Science, 2018. 435: p. 886-893.

30. Lu, D., et al., Synthesis of magnetic ZnFe2O4/graphene composite and its application in photocatalytic degradation of dyes. Journal of Alloys and Compounds, 2013. 579: p. 336342. 
31. Shen, J., et al., Facile fabrication of magnetic reduced graphene oxide-ZnFe2O4 composites with enhanced adsorption and photocatalytic activity. Applied Surface Science, 2015. 359: p. 455-468.

32. Fu, Y., X.J.I. Wang, and E.C. Research, Magnetically separable ZnFe2O4-graphene catalyst and its high photocatalytic performance under visible light irradiation. Industrial \& Engineering Chemistry Research 2011. 50(12): p. 7210-7218.

33. Yousefi, R., et al., Highly enhanced photocatalytic performance of $\mathrm{Zn}(1-x) \mathrm{MgxO} / \mathrm{rGO}$ nanostars under sunlight irradiation synthesized by one-pot refluxing method. Advanced Powder Technology, 2018. 29(1): p. 78-85.

34. Yang, S., et al., Graphene-based nanosheets with a sandwich structure. Angewandte Chemie International Edition, 2010. 49(28): p. 4795-4799.

35. $\mathrm{Wu}, \mathrm{S}$., et al., Reduced graphene oxide anchored magnetic ZnFe 2 O 4 nanoparticles with enhanced visible-light photocatalytic activity. RSC Advances, 2015. 5(12): p. 90699074.

36. Yue, H., et al., Porous hierarchical nitrogen-doped carbon coated ZnFe2O4 composites as high performance anode materials for lithium ion batteries. Electrochimica Acta, 2015. 180: p. 622-628.

37. Wu, L., et al., Electrospinning Synthesis of $\mathrm{Ni}$, Fe codoped ultrafine-ZnFe2O4/C nanofibers and their properties for lithium ion storage. Electrochimica Acta, 2016. 194: p. 357-366.

38. Quickel, T.E., et al., Mesoporous bismuth ferrite with amplified magnetoelectric coupling and electric field-induced ferrimagnetism. Nature communications, 2015. 6: p. 6562.

39. Wang, R., et al., Preparation of nitrogen-doped TiO2/graphene nanohybrids and application as counter electrode for dye-sensitized solar cells. ACS applied materials \& interfaces, 2014. 6(3): p. 2118-2124.

40. Vadivel, S., et al., Facile synthesis of novel CaFe2O4/g-C3N4 nanocomposites for degradation of methylene blue under visible-light irradiation. Journal of colloid and interface science, 2016. 480: p. 126-136.

41. Kovtun, A., et al., Accurate chemical analysis of oxygenated graphene-based materials using X-ray photoelectron spectroscopy. Carbon, 2019. 143: p. 268-275.

42. Ren, H., et al., Surface functionality analysis by Boehm titration of graphene nanoplatelets functionalized via a solvent-free cycloaddition reaction. Nanoscale Advances, 2019. 1(4): p. 1432-1441.

43. La, D.D., et al., Fabrication of a GNP/Fe-Mg binary oxide composite for effective removal of arsenic from aqueous solution. ACS Omega, 2017. 2(1): p. 218-226.

44. Shuang-Shuang, Z., et al., Functionalization of carbon nanotubes/graphene by polyoxometalates and their enhanced photo-electrical catalysis. Chinese Physics B, 2014. 23(8): p. 088801.

45. Mohamed, M.M., I. Ibrahim, and T.M.J.A.C.A.G. Salama, Rational design of manganese ferrite-graphene hybrid photocatalysts: efficient water splitting and effective elimination of organic pollutants. Applied Catalysis A: General, 2016. 524: p. 182-191.

46. Devi, L.G. and M.J.J.o.e.c.e. Srinivas, Hydrothermal synthesis of reduced graphene oxide-CoFe2O4 heteroarchitecture for high visible light photocatalytic activity: Exploration of efficiency, stability and mechanistic pathways. Journal of environmental chemical engineering, 2017. 5(4): p. 3243-3255.

47. Li, X., et al., Graphene in photocatalysis: a review. Small, 2016. 12(48): p. 6640-6696. 
48. $\mathrm{Li}, \mathrm{B}$., et al., Graphene quantum dots decorated $\mathrm{ZnO}-\mathrm{ZnFe} 2 \mathrm{O} 4$ nanocages and their visible light photocatalytic activity. Applied Surface Science, 2019.

49. Chen, C.-H., et al., ZnFe2O4/MWCNTs composite with enhanced photocatalytic activity under visible-light irradiation. Journal of Alloys and Compounds, 2010. 501(1): p. 168172.

50. Arshad, A., J. Iqbal, and Q.J.N. Mansoor, NiO-nanoflakes grafted graphene: an excellent photocatalyst and a novel nanomaterial for achieving complete pathogen control. Nanoscale, 2017. 9(42): p. 16321-16328.

51. Wang, H., et al., Asymmetric Supercapacitors Assembled by Dual Spinel Ferrites@ Graphene Nanocomposites as Electrodes. ACS Applied Energy Materials, 2018. 1(7): p. 3206-3215.

52. Zhang, J., et al., A high-performance asymmetric supercapacitor fabricated with graphene-based electrodes. Energy \& Environmental Science, 2011. 4(10): p. 40094015.

53. Liu, Y., et al., Layered-MnO2 nanosheet grown on nitrogen-doped graphene template as a composite cathode for flexible solid-state asymmetric supercapacitor. ACS applied materials \& interfaces, 2016. 8(8): p. 5251-5260.

54. Tang, Y. and B.J.E. Cheng, 3D self-supported hierarchical NiCo architectures with integrated capacitive performance and enhanced electronic conductivity for supercapacitors. Energy, 2016. 112: p. 755-761.

55. Liu, B., et al., MnO2 nanostructures deposited on graphene-like porous carbon nanosheets for high-rate performance and high-energy density asymmetric supercapacitors. ACS Sustainable Chemistry \& Engineering, 2019.7 (3): p. 3101-3110.

56. Vadivel, S., et al., Solvothermal synthesis of BiPO4 nanorods/MWCNT (1D-1D) composite for photocatalyst and supercapacitor applications. Ceramics International, 2016. 42(12): p. 14196-14205.

57. Vijayakumar, S., et al., Porous NiO/C nanocomposites as electrode material for electrochemical supercapacitors. ACS Sustainable Chemistry \& Engineering, 2013. 1(9): p. 1110-1118.

58. Li, Q., et al., Highly efficient visible-light-driven photocatalytic hydrogen production of CdS-cluster-decorated graphene nanosheets. ACS applied materials \& interfaces, 2011. 133(28): p. 10878-10884.

59. Guo, S., et al., Graphene oxide-Fe2O3 hybrid material as highly efficient heterogeneous catalyst for degradation of organic contaminants. Carbon, 2013. 60: p. 437-444. 


\section{List of Figures}

Fig. 1: XRD patterns of $(\mathrm{ZF})_{1-\mathrm{x}}(\mathrm{GNPs})_{\mathrm{x}}$ samples.

Fig. 2: TEM micrographs of $(\mathrm{ZF})_{1-\mathrm{x}}(\mathrm{GNPs})_{\mathrm{x}}$ samples (inset: HRTEM image of ZF).

Fig. 3: XPS wide angle spectra for $(\mathrm{ZF})_{1-\mathrm{x}}(\mathrm{GNPs})_{\mathrm{x}}$ nanocomposites.

Fig. 4: (a) DRS spectra of $(\mathrm{ZF})_{1-\mathrm{x}}(\mathrm{GNPs})_{\mathrm{x}}$ nanocomposites (b) Kubelka-Munk plot of $(\mathrm{ZF})_{1-}$ $x(\text { GNPs })_{\mathrm{x}}$ nanocomposites.

Fig. 5: PL spectra of $(\mathrm{ZF})_{1-\mathrm{x}}(\mathrm{GNPs})_{\mathrm{x}}$ nanocomposites.

Fig. 6: Comparison of $\mathrm{CV}$ curves of $(\mathrm{ZF})_{1-\mathrm{x}}(\mathrm{GNPs})_{\mathrm{x}}$ electrodes at $5 \mathrm{mV} \mathrm{s}^{-1}$

Fig. 7: (a-e) CV curves of the $(\mathrm{ZF})_{1-\mathrm{x}}(\mathrm{GNPs})_{\mathrm{x}}$ electrodes at various scan rate.

Fig. 8: Comparison of GDC curves of $(\mathrm{ZF})_{1-\mathrm{x}}(\mathrm{GNPs})_{\mathrm{x}}$ electrodes at $0.5 \mathrm{Ag}^{-1}$

Fig. 9: (a-e) GDC curves of the $(\mathrm{ZF})_{1-\mathrm{x}}(\mathrm{GNPs})_{\mathrm{x}}$ electrodes at various current densities.

Fig. 10: (a) Specific capacitance curves of $(\mathrm{ZF})_{1-\mathrm{x}}(\mathrm{GNPs})_{\mathrm{x}}$ electrodes at various current densities

(b) Ragone plots of $(\mathrm{ZF})_{1-\mathrm{x}}(\mathrm{GNPs})_{\mathrm{x}}$ electrodes.

Fig. 11: (a) EIS spectra of $(\mathrm{ZF})_{1-\mathrm{x}}(\mathrm{GNPs})_{\mathrm{x}}$ electrodes in the frequency range $100 \mathrm{kHz}-0.1 \mathrm{~Hz}$

(b) Cycling stability of $(\mathrm{ZF})_{1-\mathrm{x}}(\mathrm{GNPs})_{\mathrm{x}}$ electrodes.

Fig. 12: Photo degradation of $(\mathrm{ZF})_{1-\mathrm{x}}(\mathrm{GNPs})_{\mathrm{x}}$ nanocomposites

Fig. 13: (a-e) Absorption spectra of MB solution for $(\mathrm{ZF})_{1-\mathrm{x}}(\mathrm{GNPs})_{\mathrm{x}}$ nanocomposites at respective time intervals.

Fig. 14: Schematic representation of photodegradation mechanism of MB by $(\mathrm{ZF})_{1-\mathrm{x}}(\mathrm{GNPs})_{\mathrm{x}}$ nanocomposites 
Fig. 1:

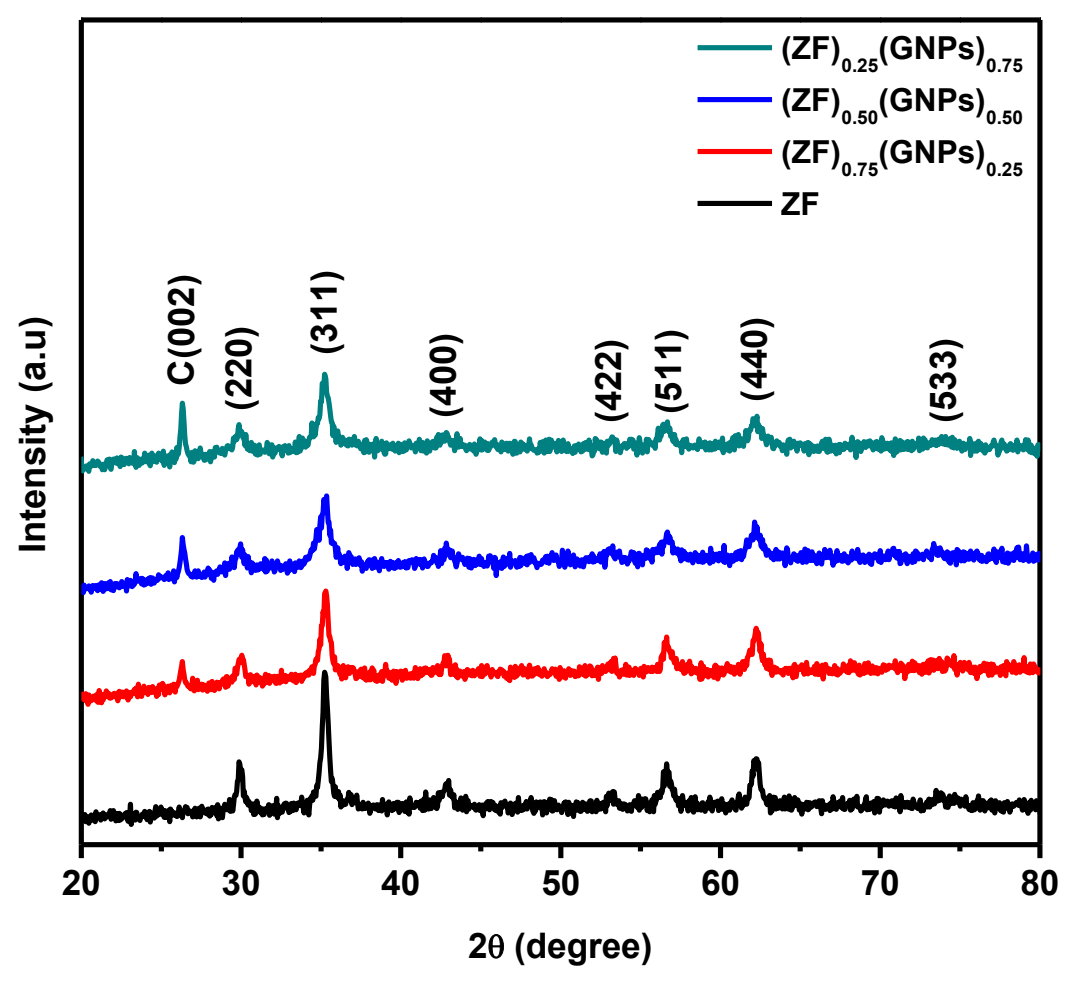


Fig. 2 (a)

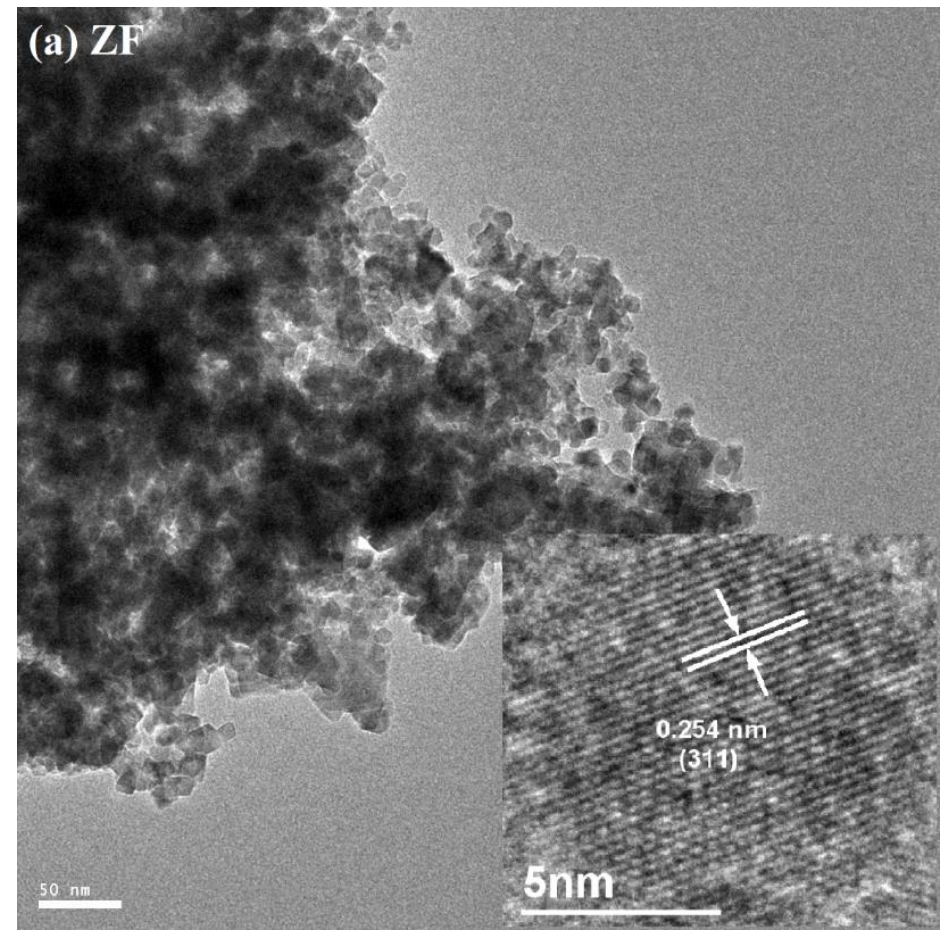


Fig. 2 (b)

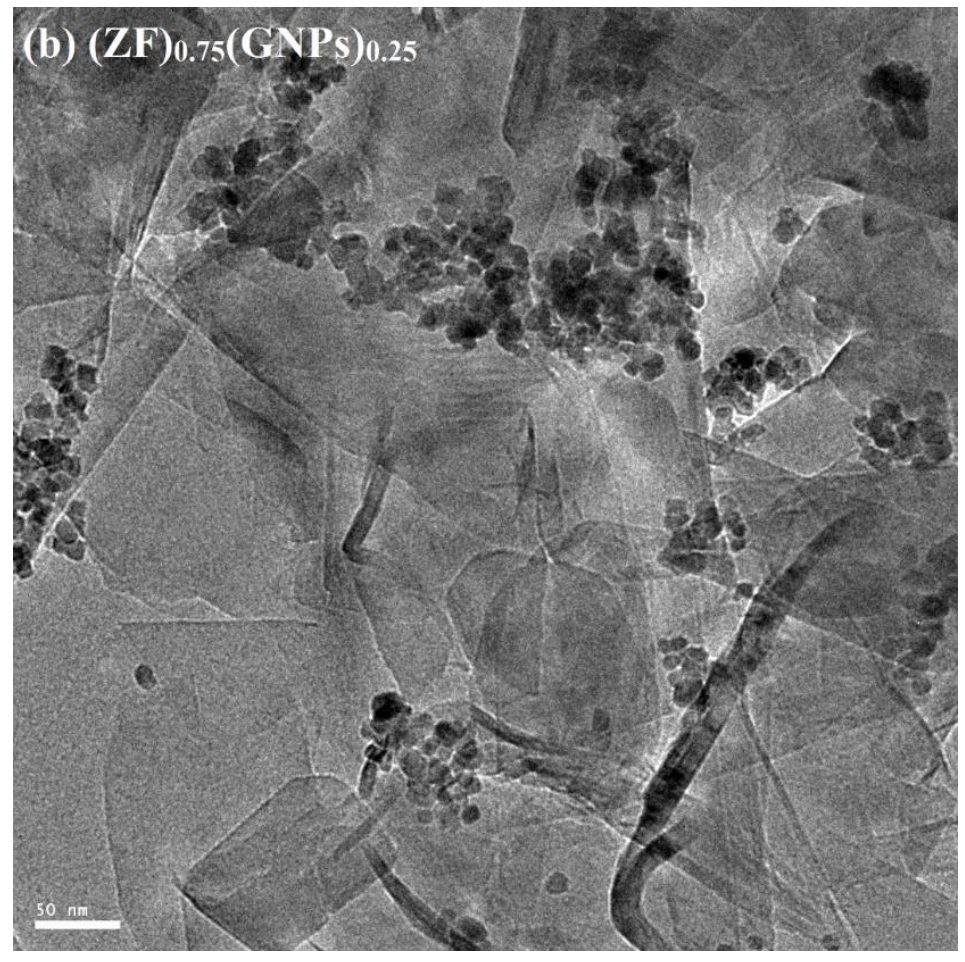


Fig. 2 (c)

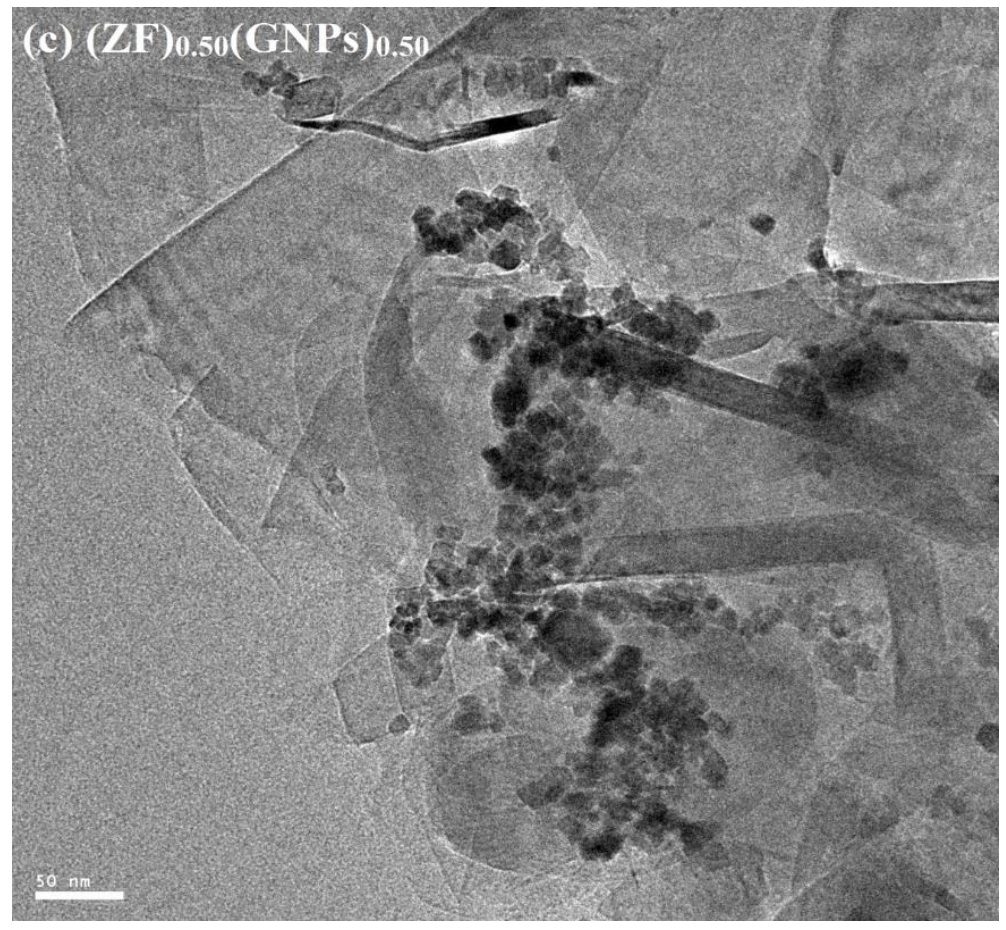


Fig. 2 (d)

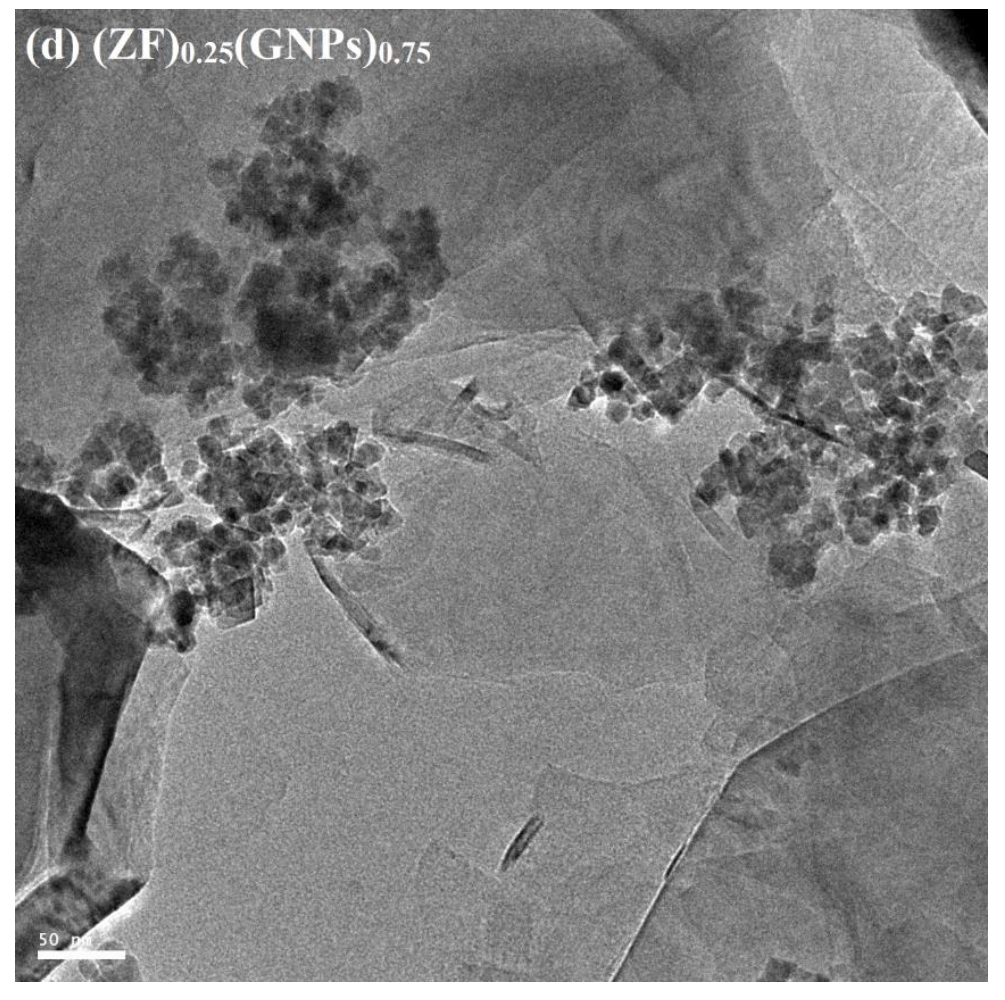


Fig. 3 (a)

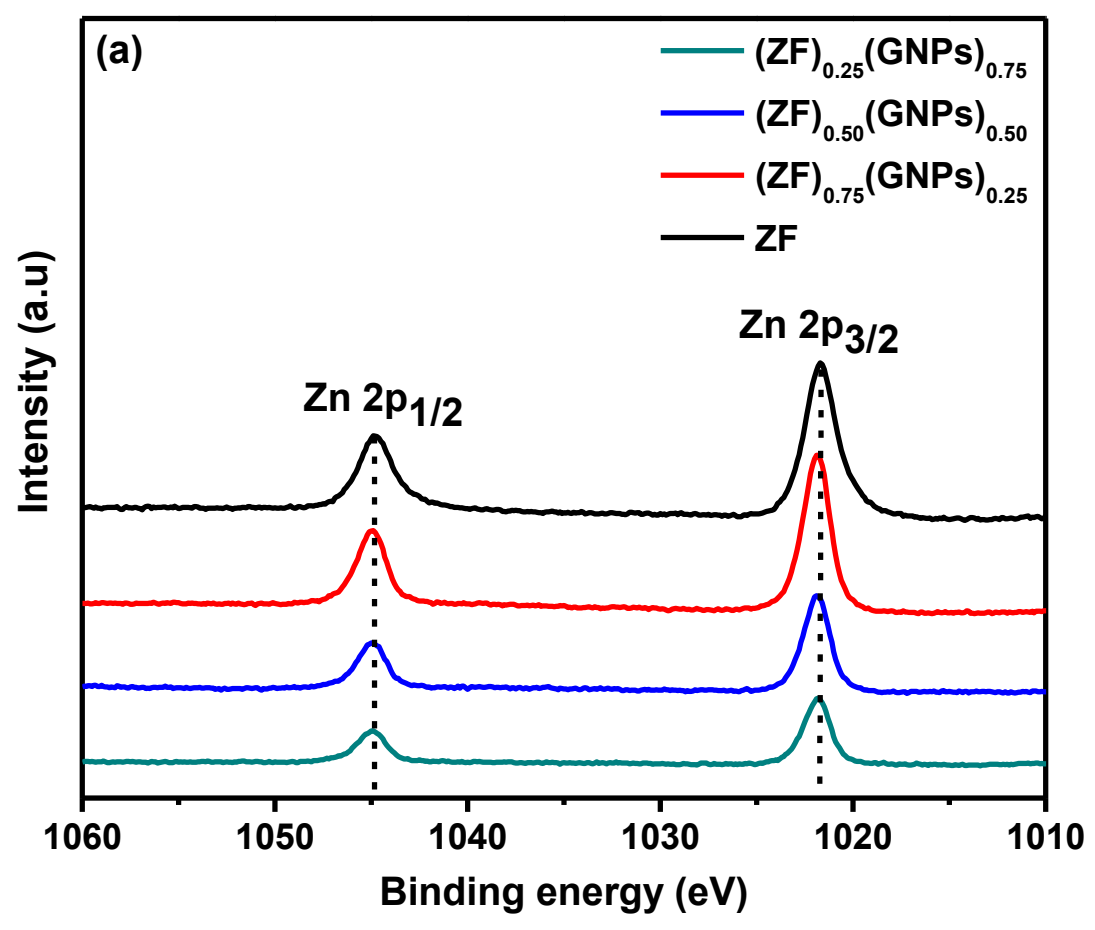


Fig. 3 (b)

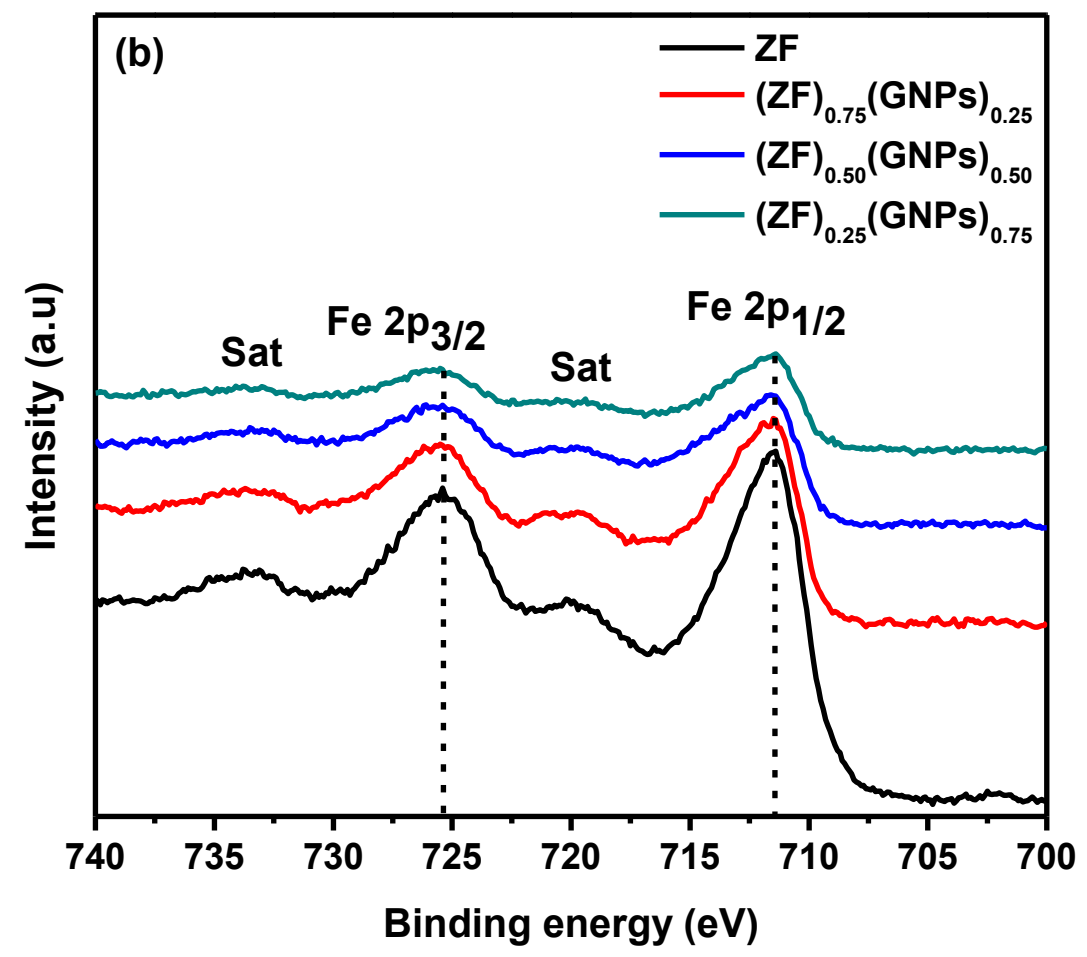


Fig. 3 (c)

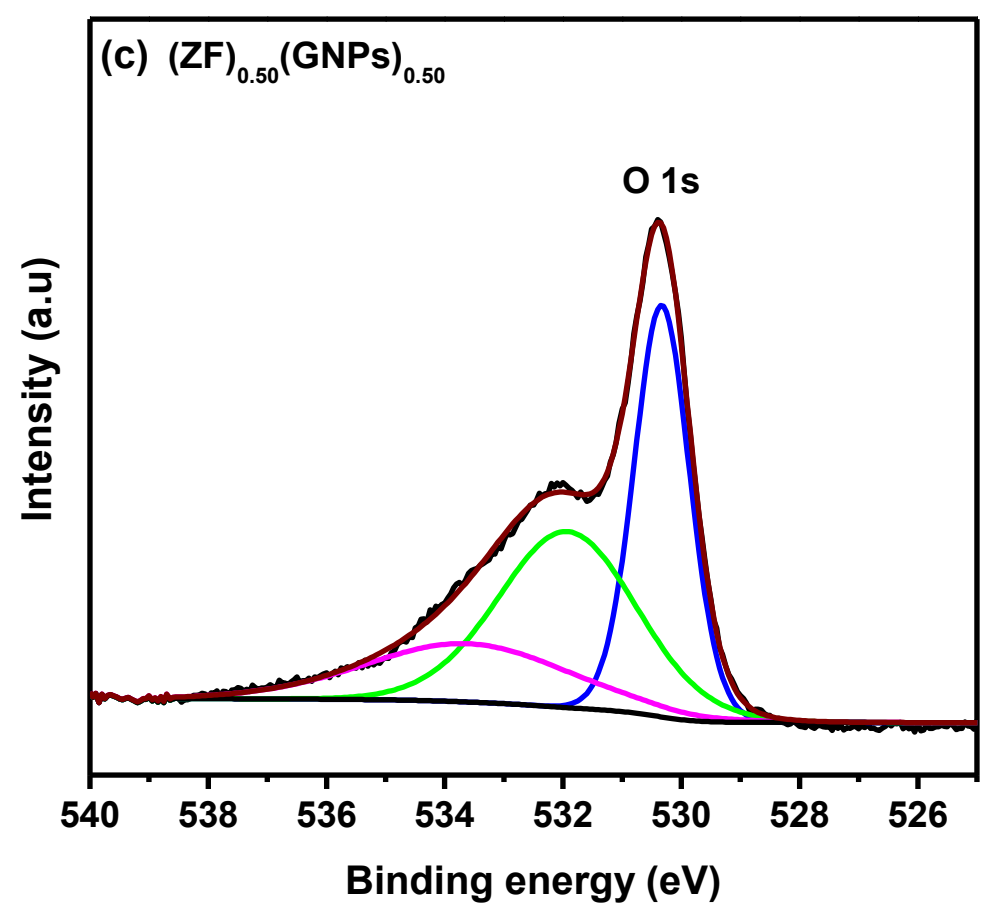


Fig. 3 (d)

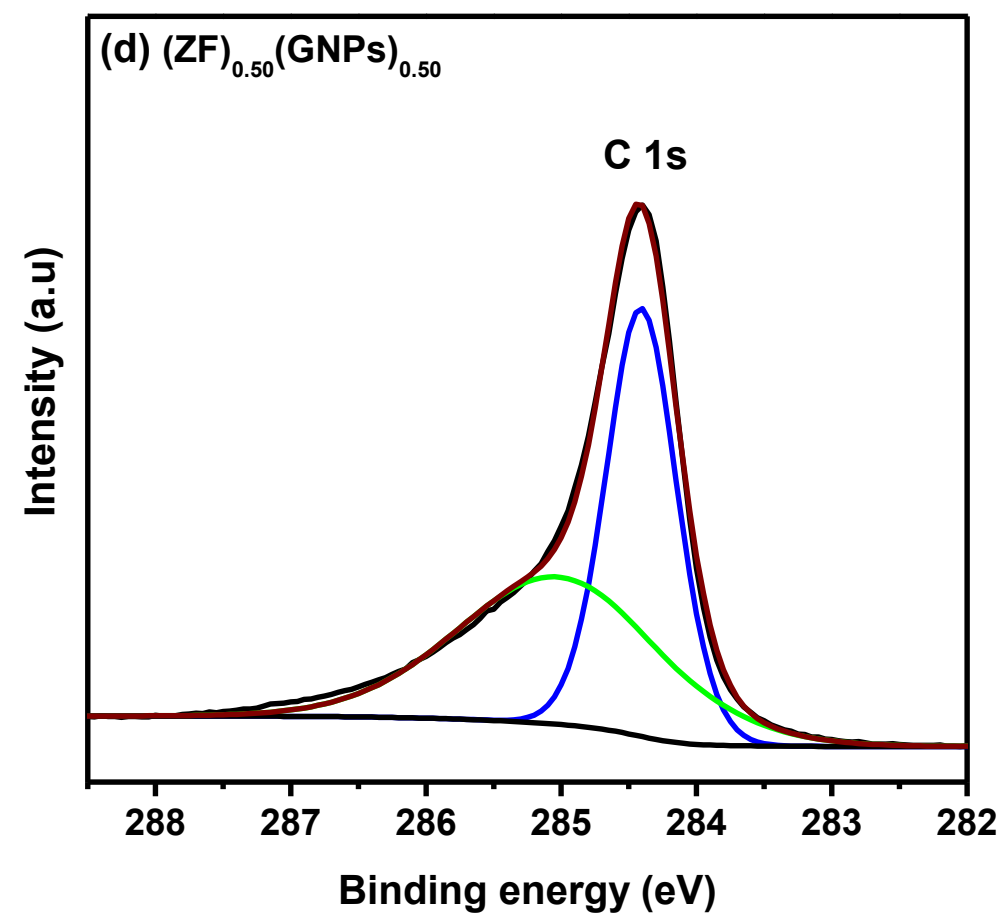


Fig. 4 (a)

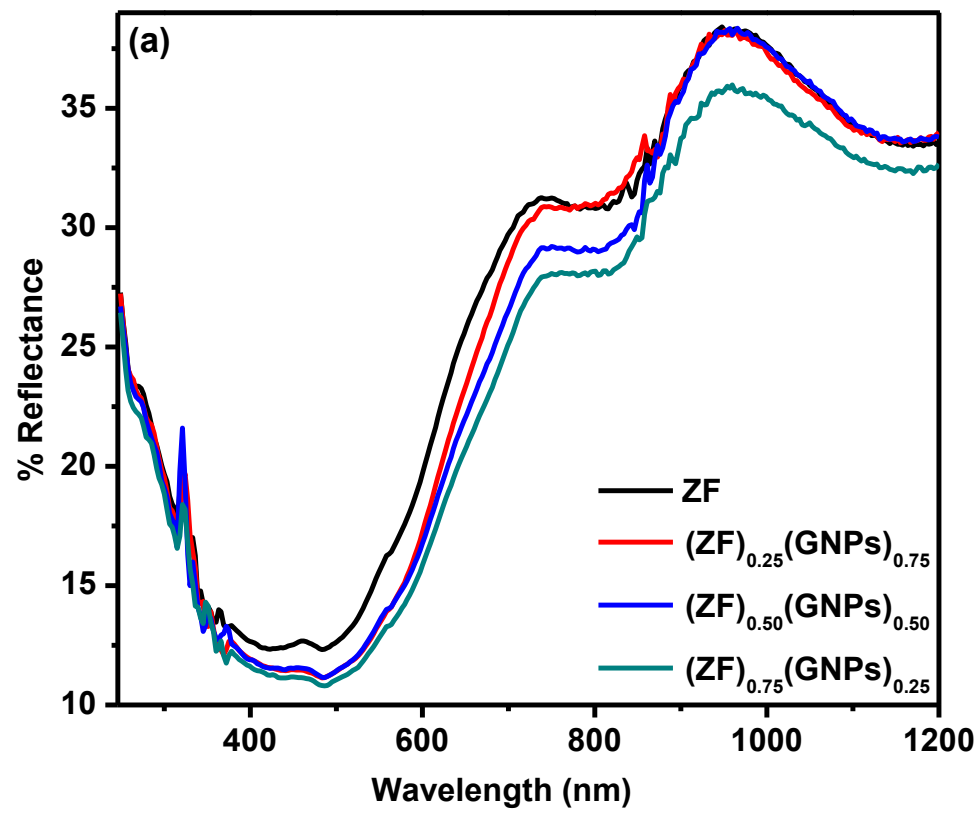


Fig. 4 (b)

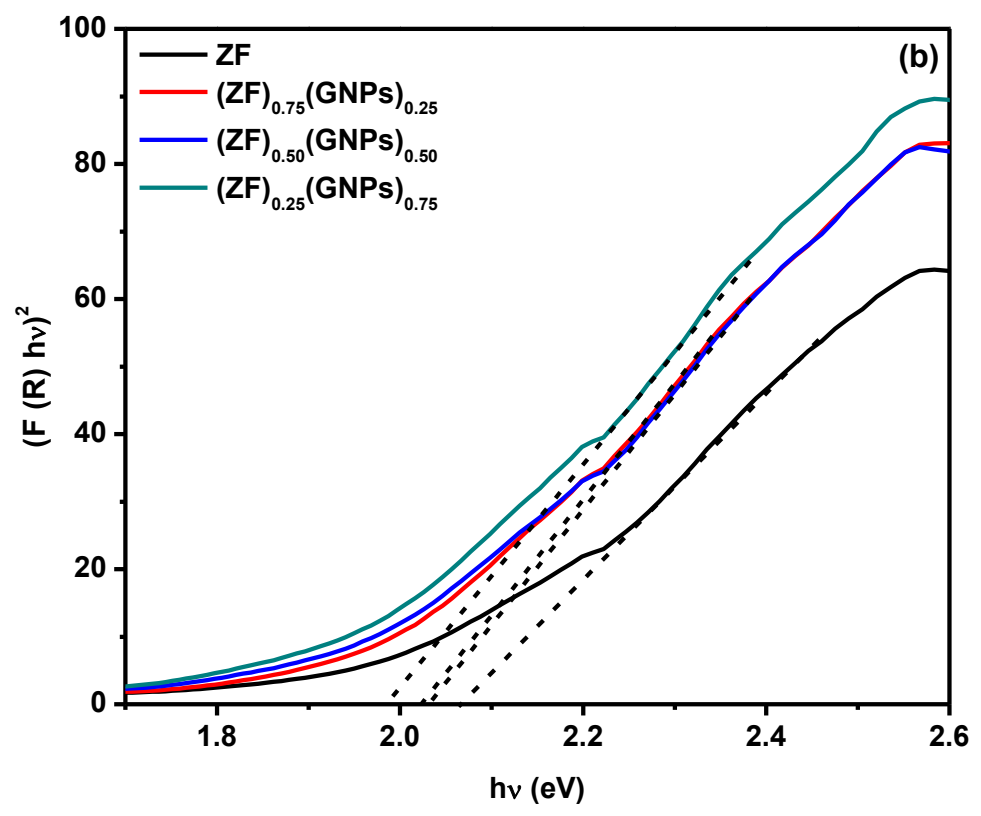


Fig. 5

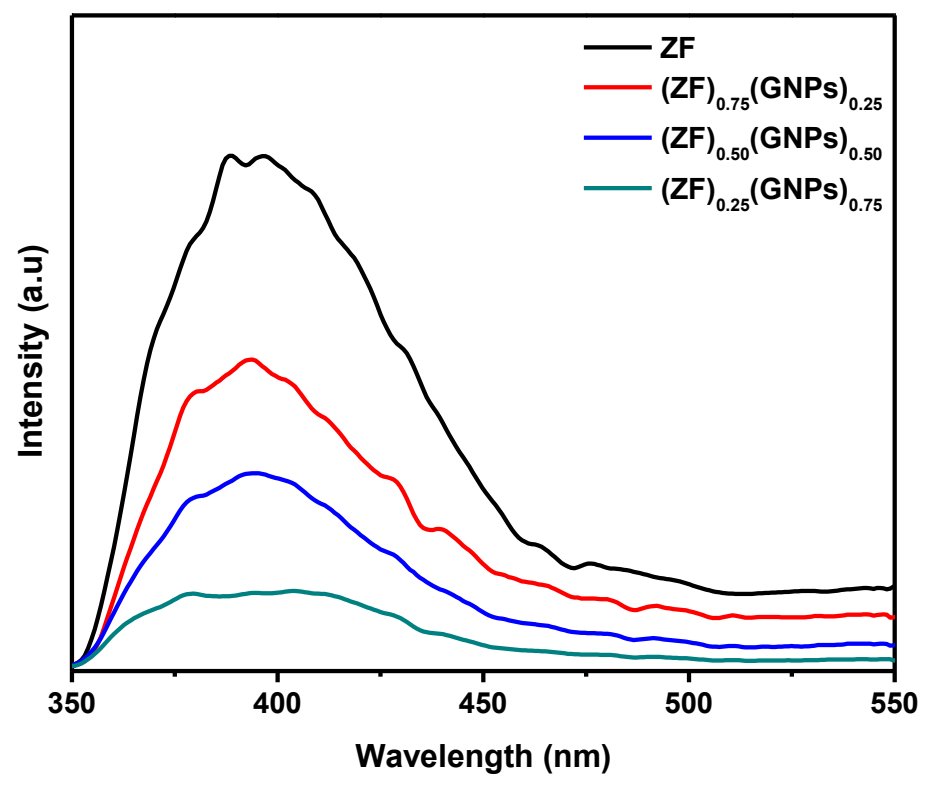


Fig. 6

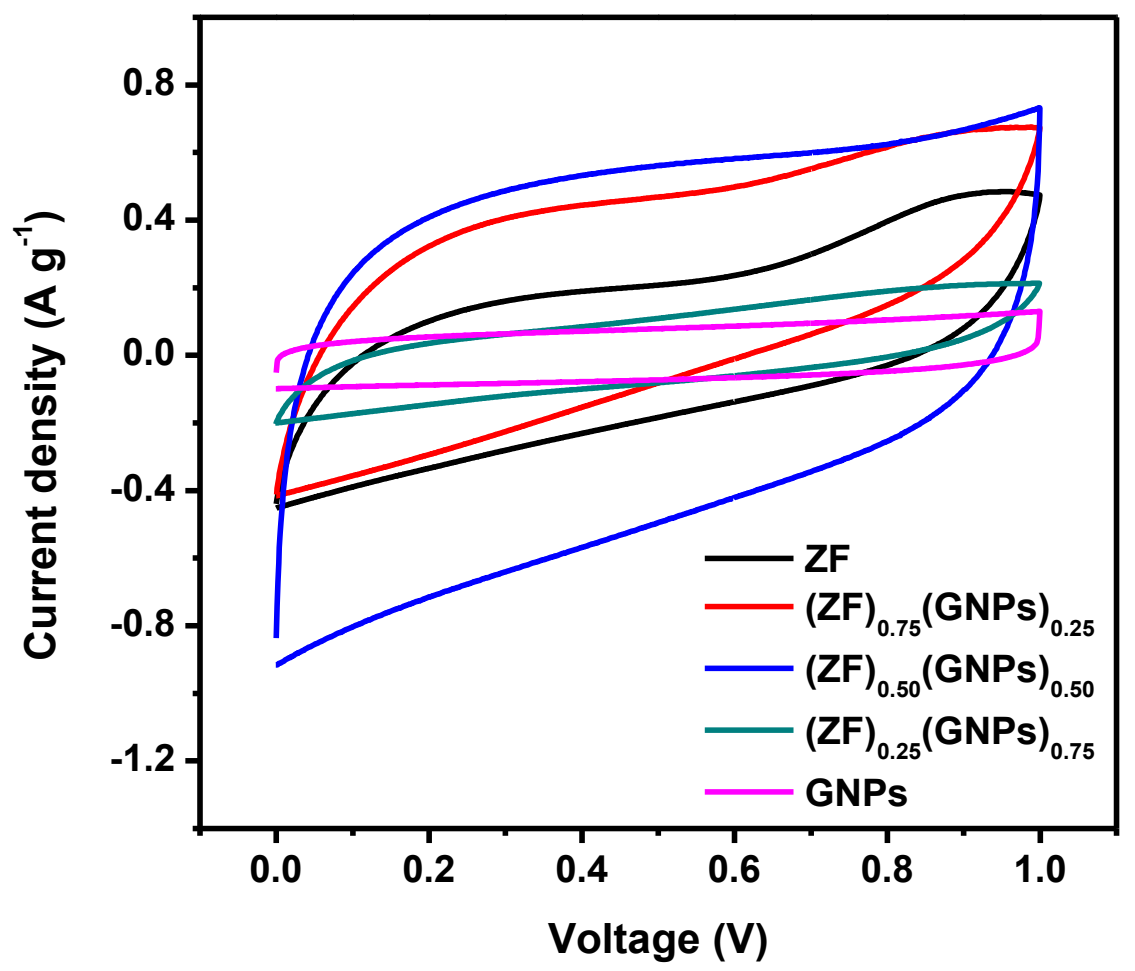


Fig. 7 (a)

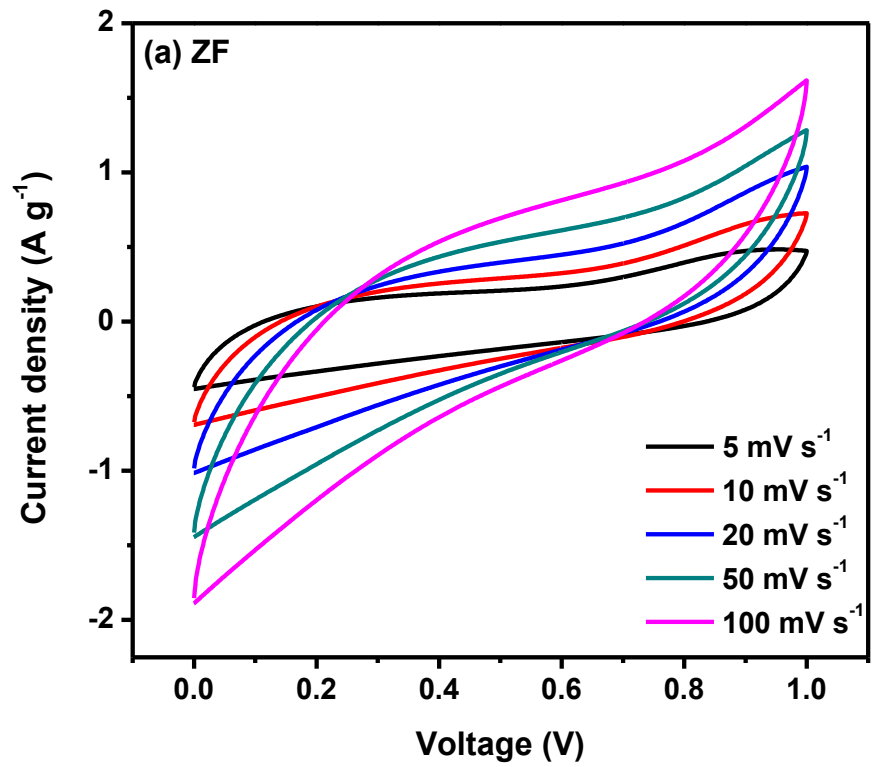


Fig. 7 (b)

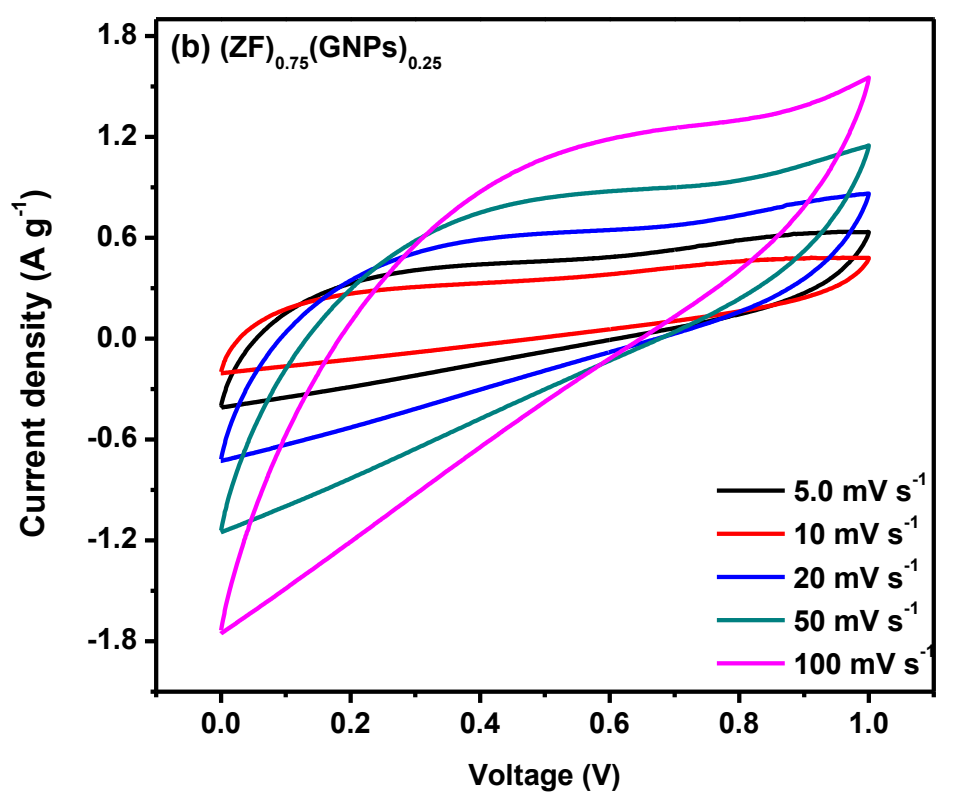


Fig. 7 (c)

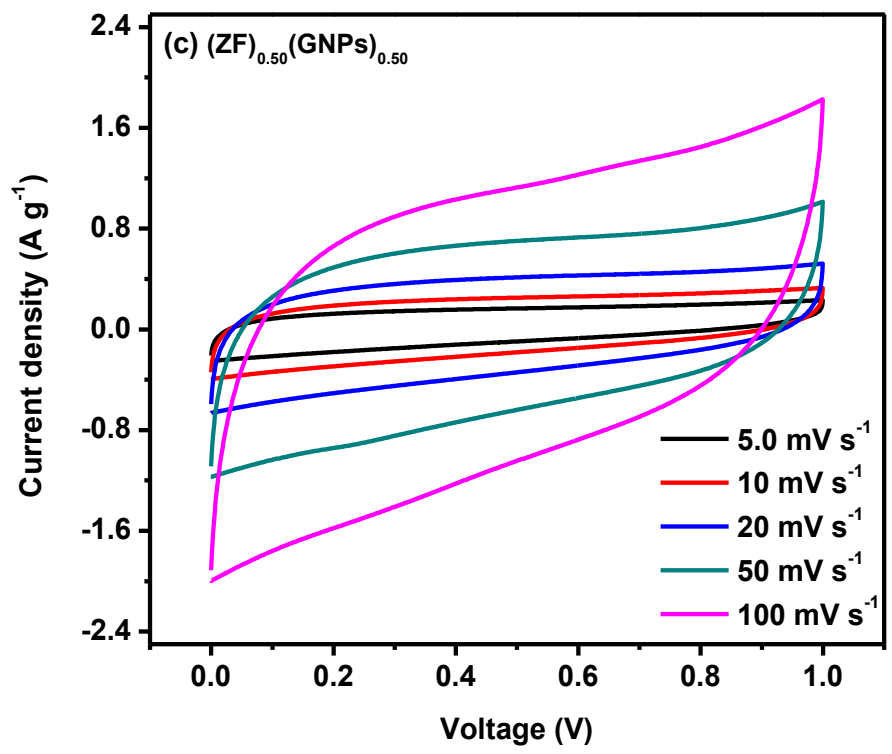


Fig. 7 (d)

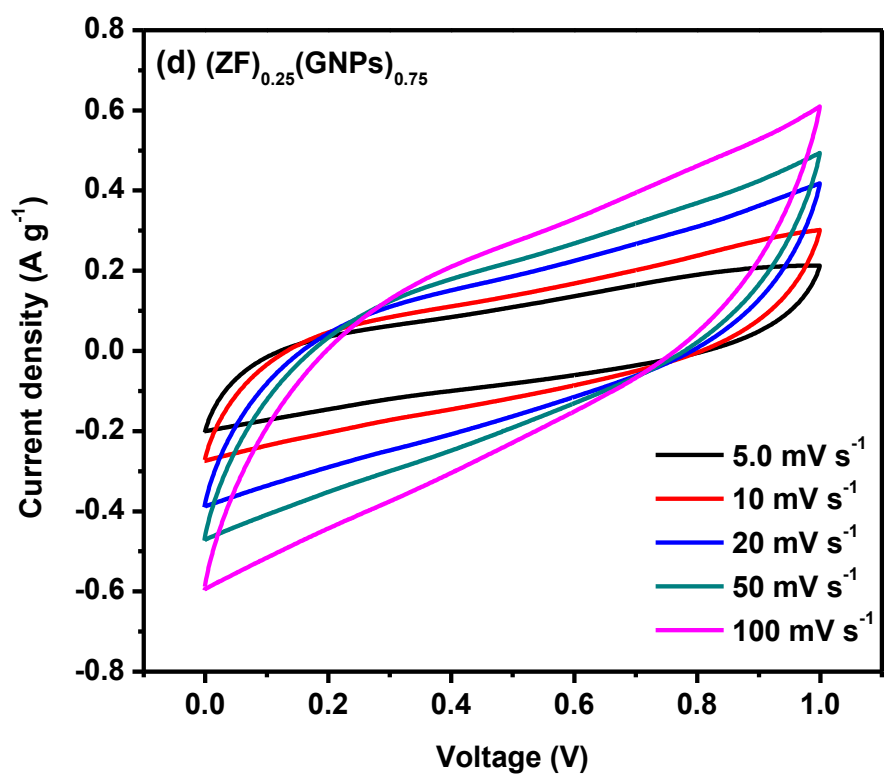


Fig. 7 (e)

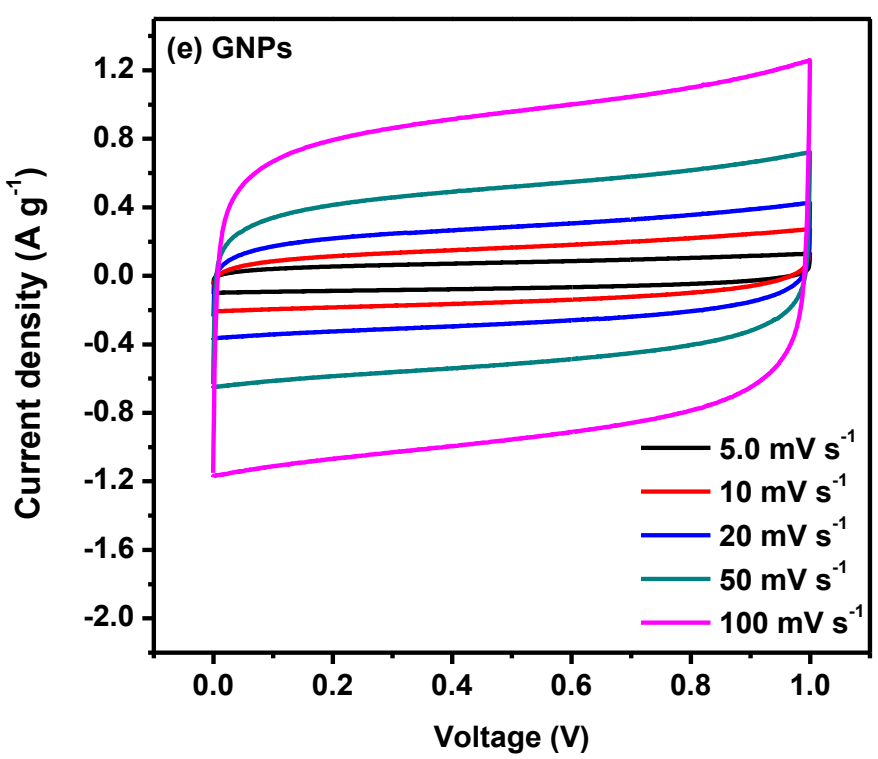


Fig. 8

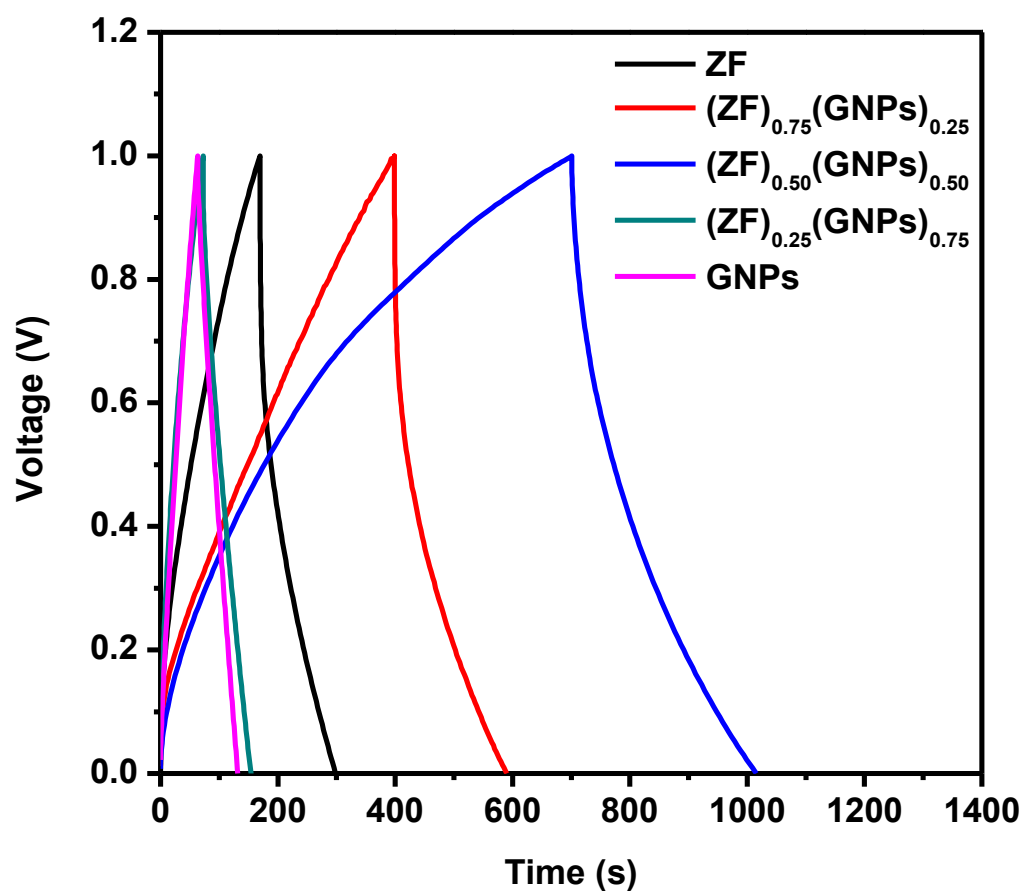


Fig. 9 (a)

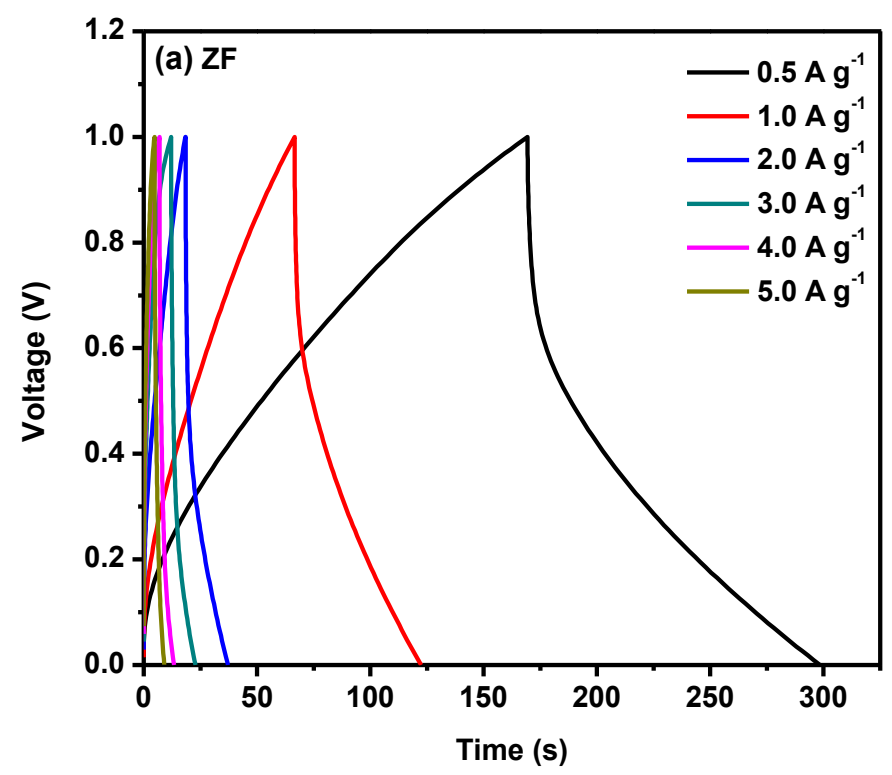


Fig. 9 (b)

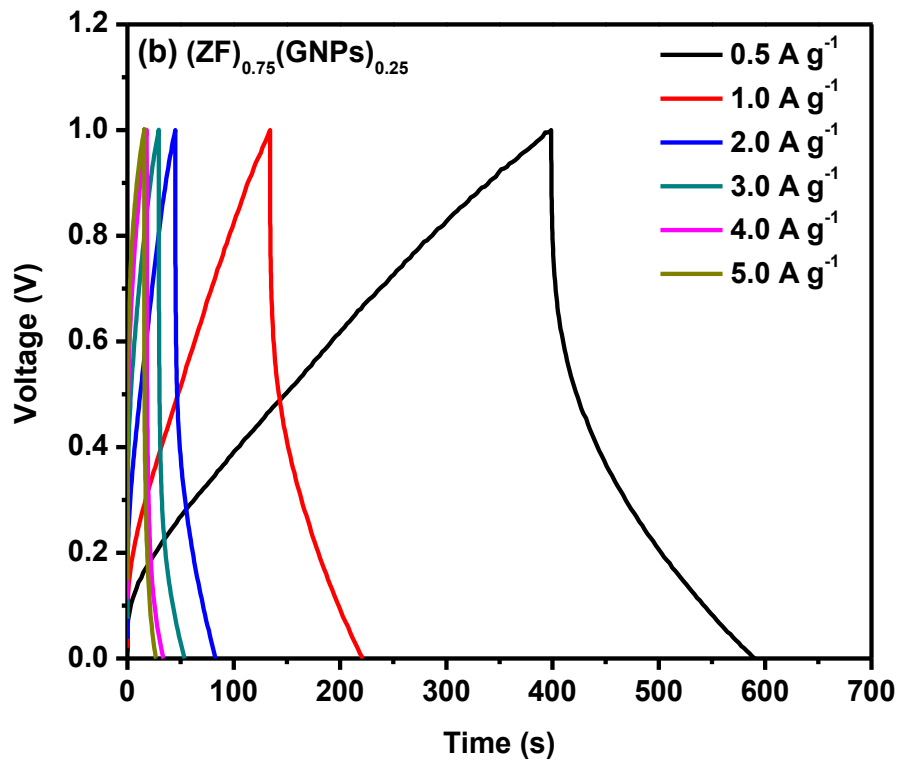


Fig. 9 (c)

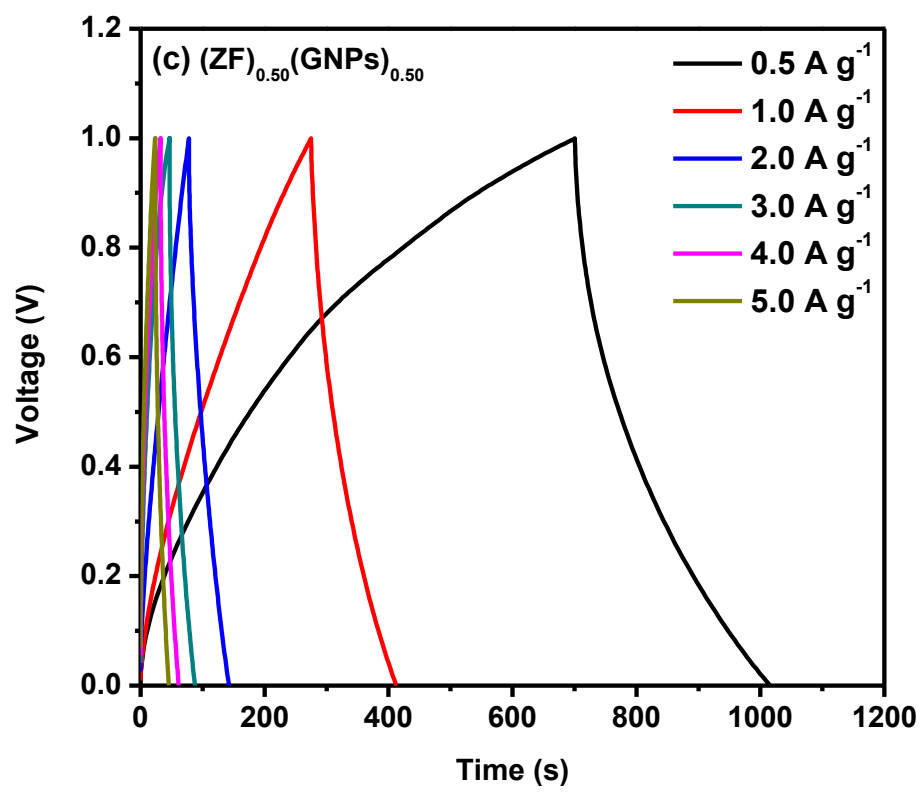


Fig. 9 (d)

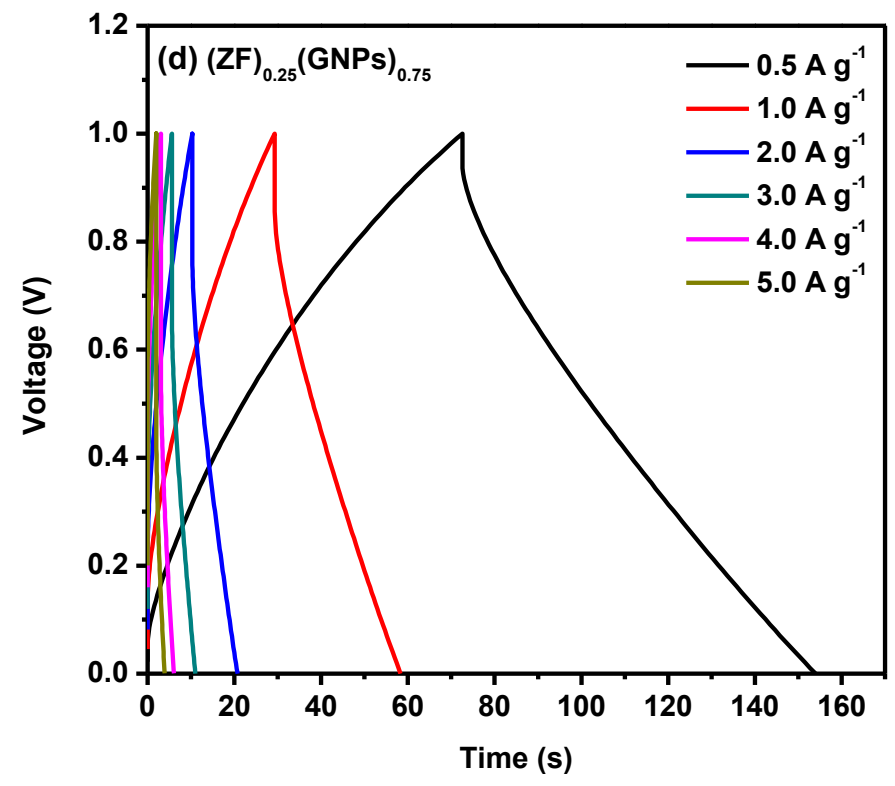


Fig.9 (e)

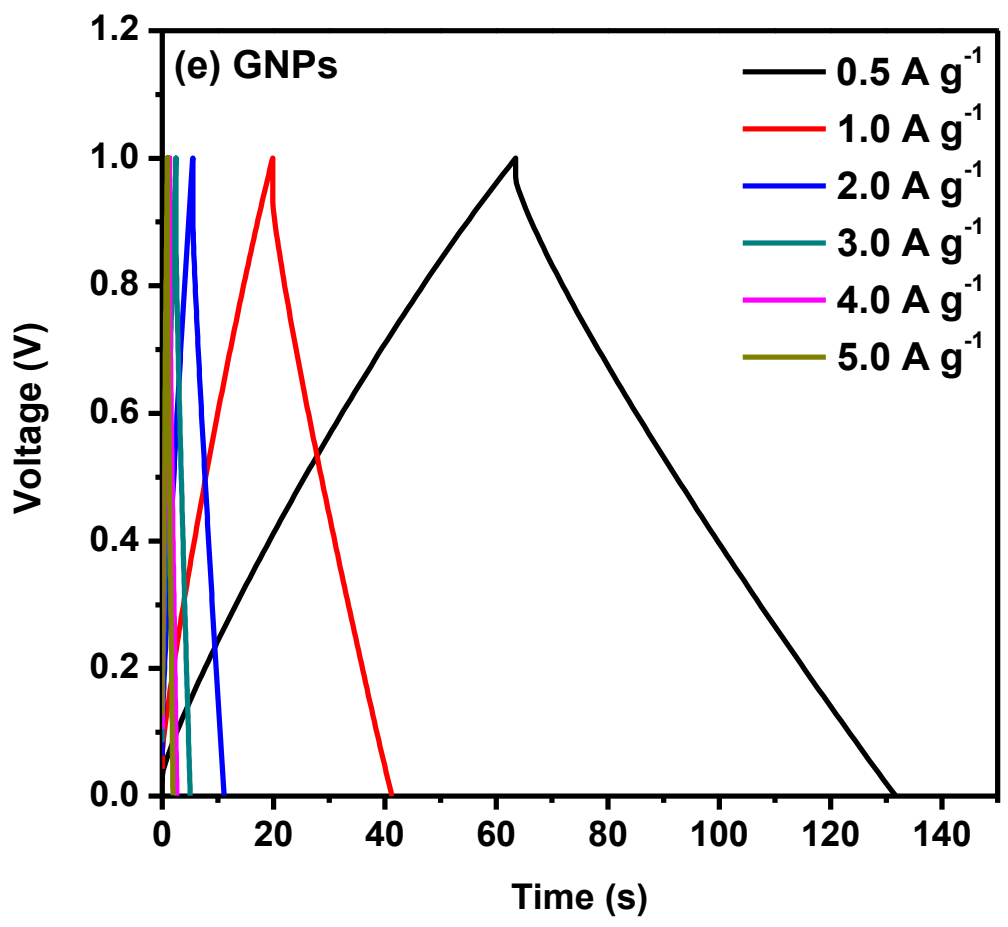


Fig. 10 (a):

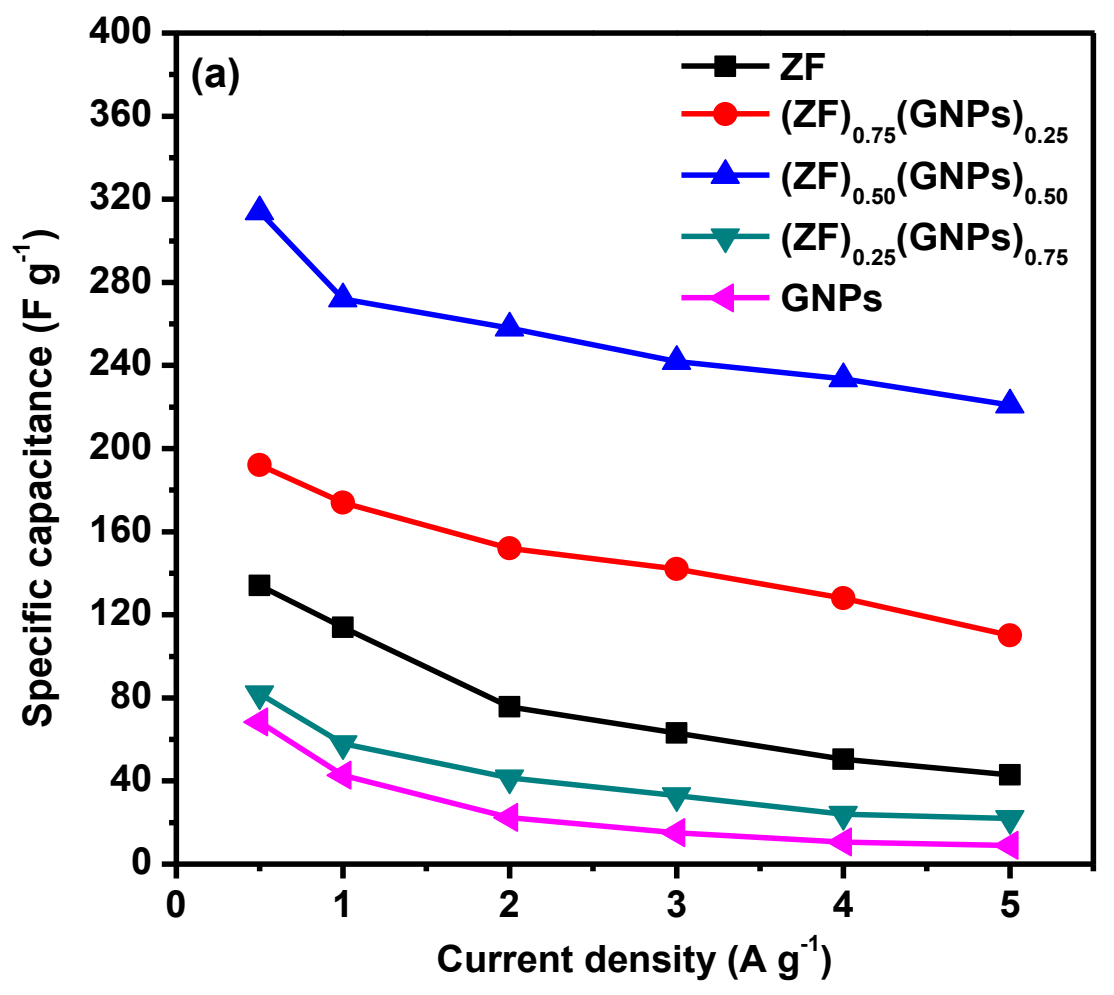


Fig. 10 (b):

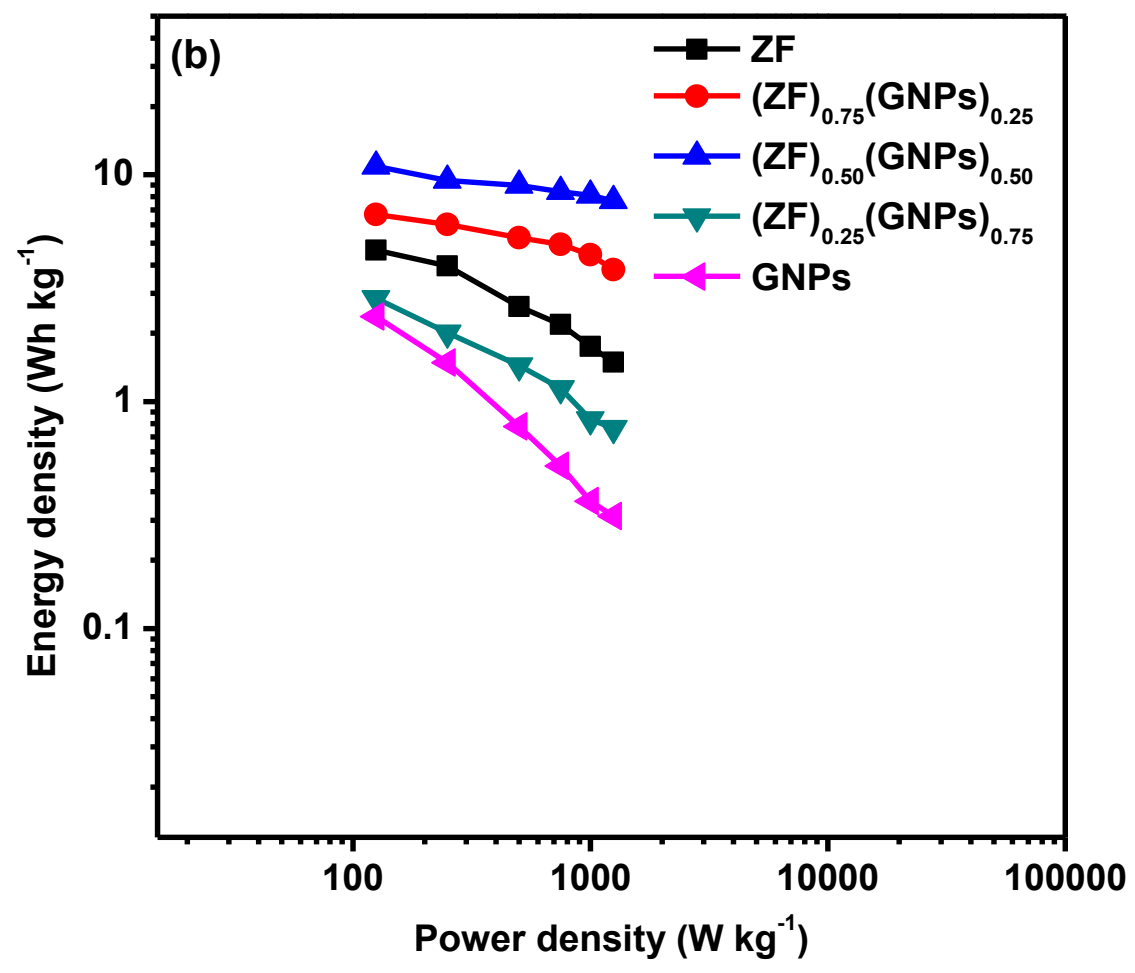

Fig. 11 (a): 


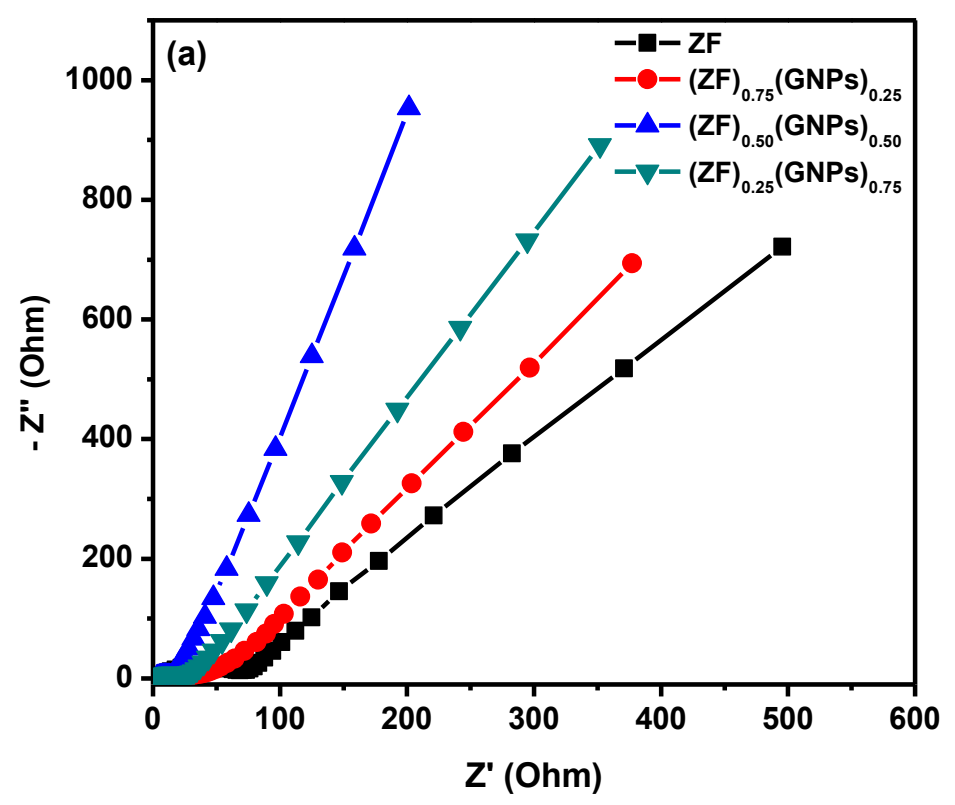


Fig. 11 (b):

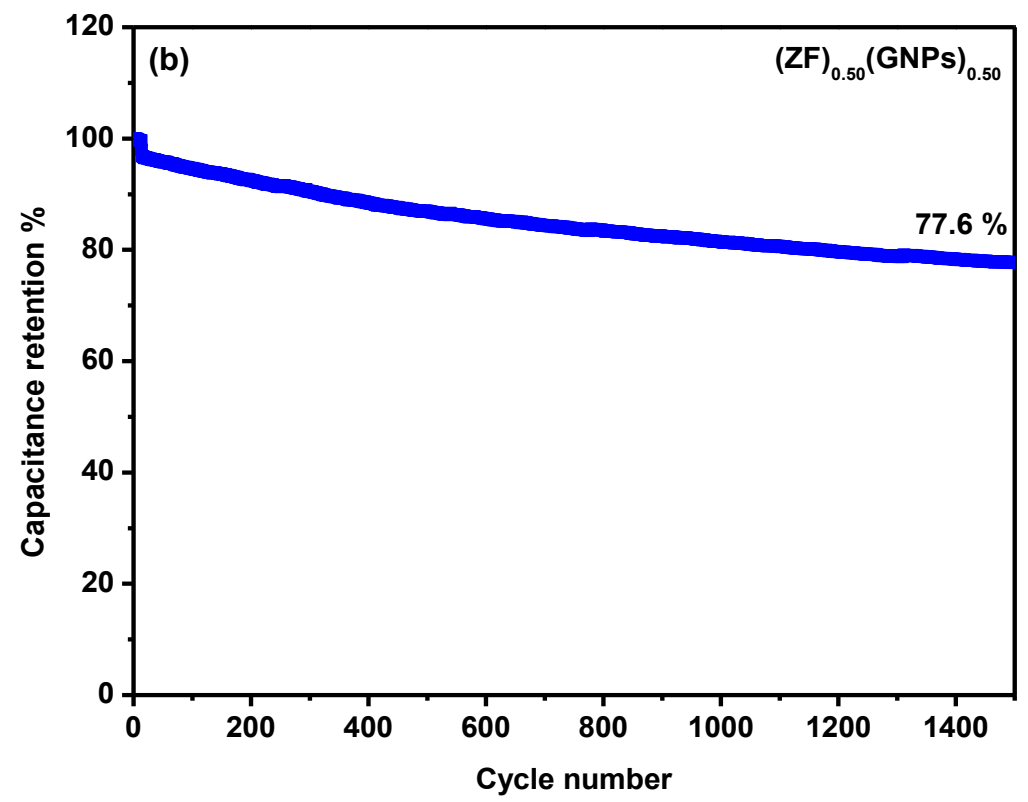


Fig. 12:

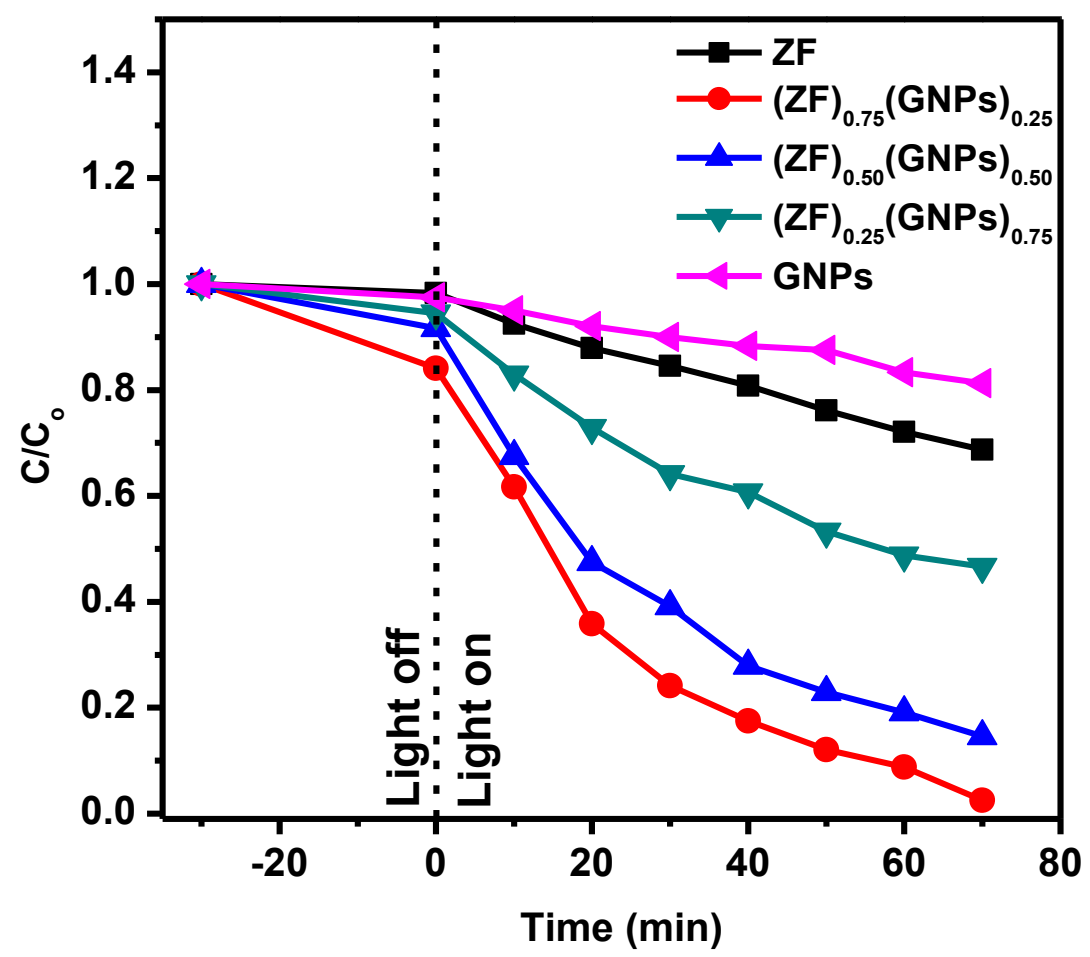


Fig. 13 (a):

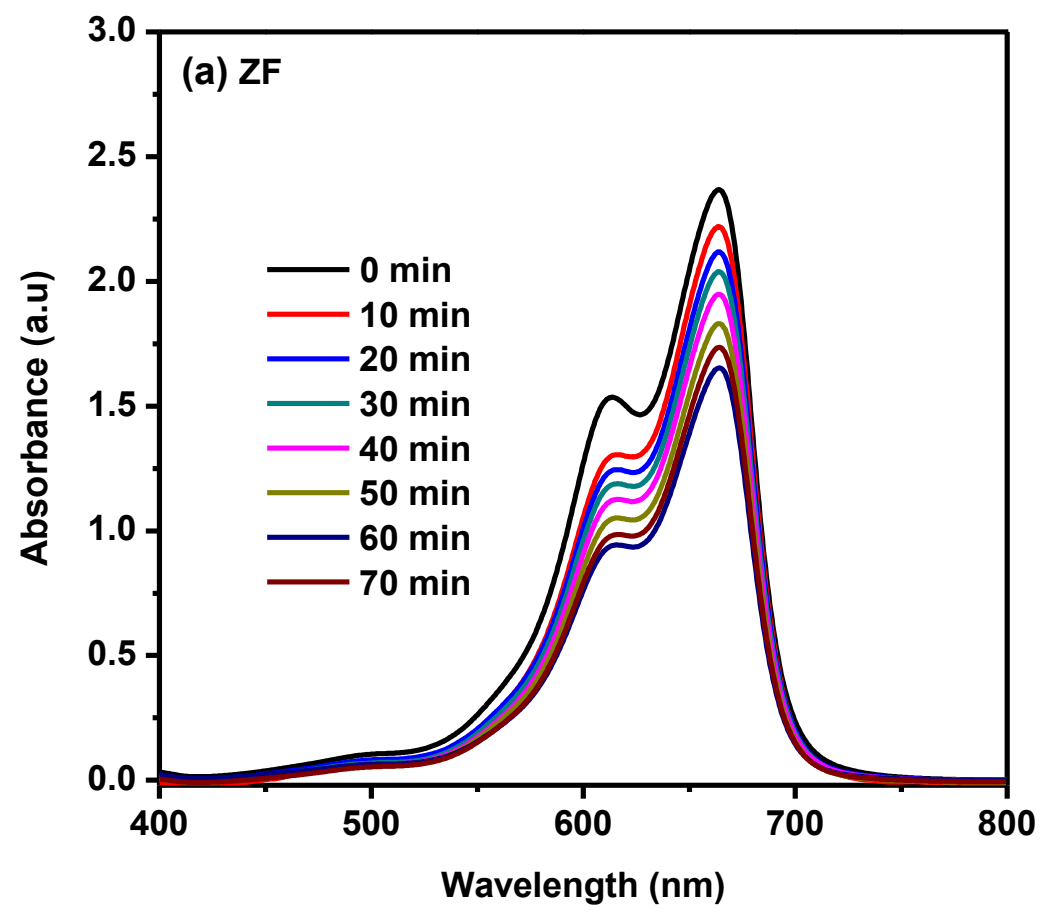


Fig. 13 (b)

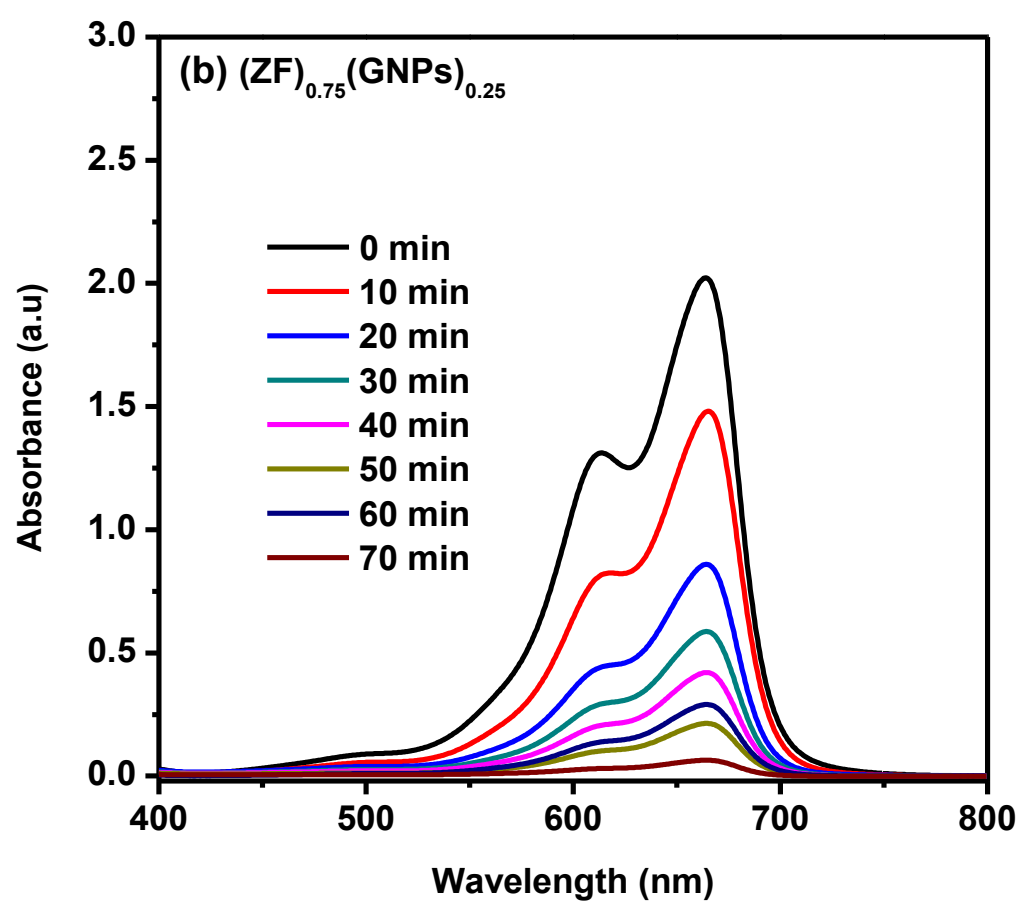


Fig. 13 (c):

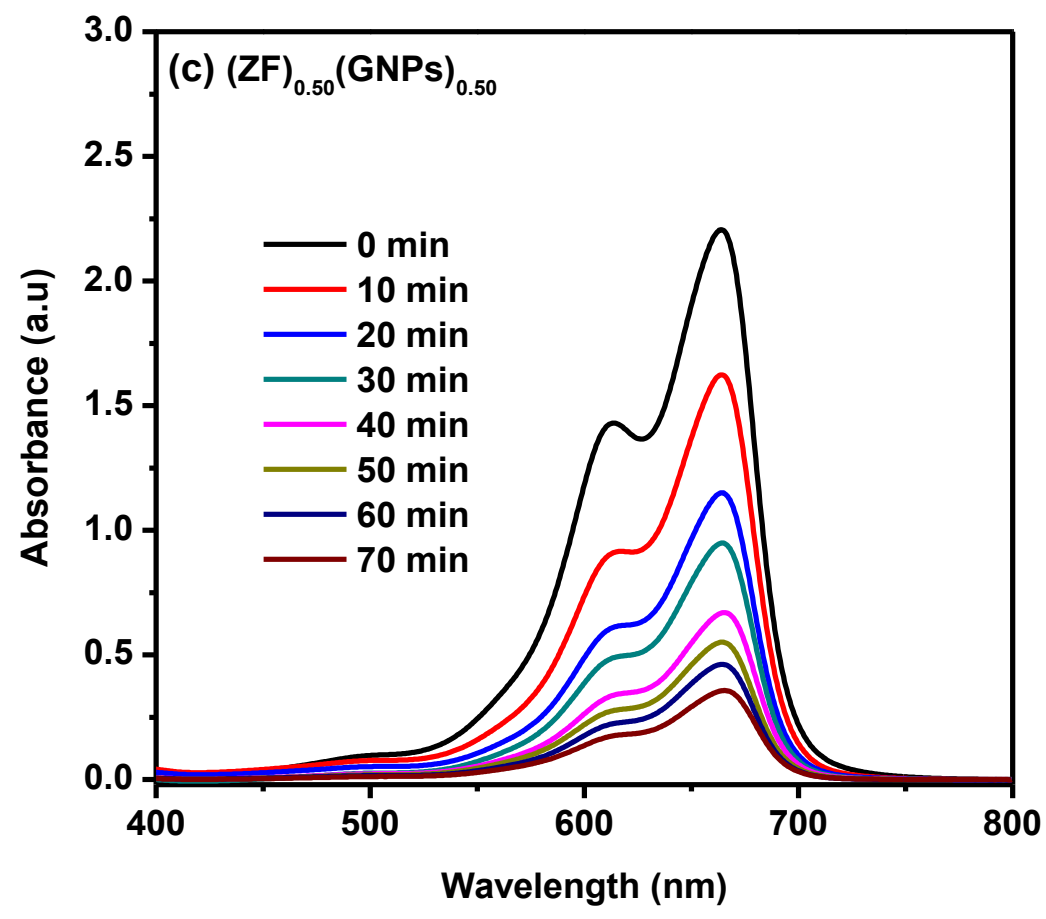


Fig. 13 (d)

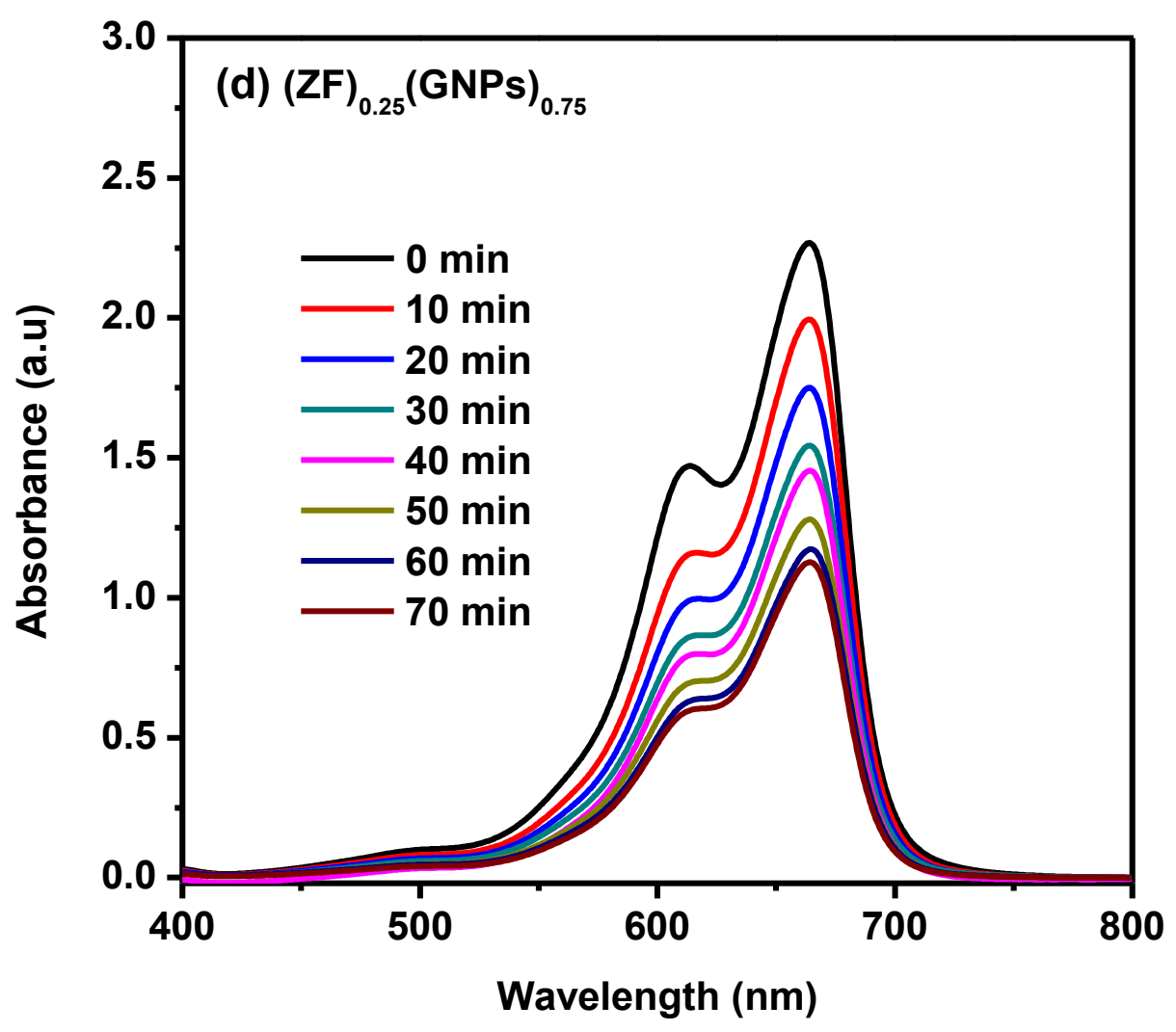

Fig. 14: 


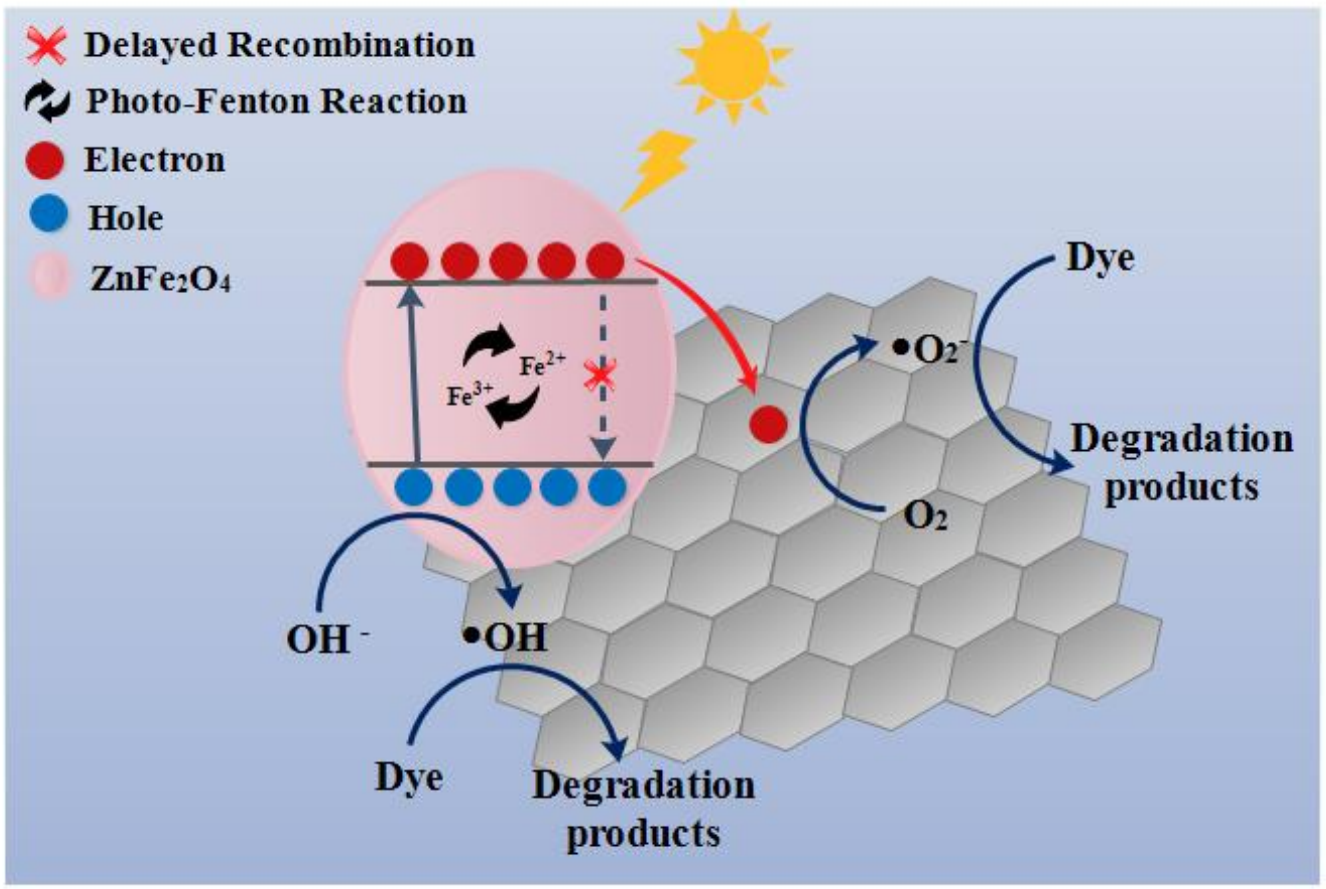

